\title{
G sonstam \\ Preferred Hierarchical Control Strategy of Non-Point Source Pollution at Regional Scale
}

\section{Weijia Wen}

Chinese Academy of Sciences Innovation Academy for Precision Measurement Science and Technology

Yanhua Zhuang ( $\sim$ zhuang@whigg.ac.cn )

Institute of Geodesy and Geophysics Chinese Academy of Sciences https://orcid.org/0000-0002-7041-

1118

\section{Liang Zhang}

Chinese Academy of Sciences Innovation Academy for Precision Measurement Science and Technology

Sisi Li

Chinese Academy of Sciences Innovation Academy for Precision Measurement Science and Technology Shuhe Ruan

Chinese Academy of Sciences Innovation Academy for Precision Measurement Science and Technology Qinjing Zhang

Wuhan University

\section{Research Article}

Keywords: Non-point source (NPS) pollution, Critical periods (CPs), Critical source areas (CSAs), Dualstructure export empirical model, Point density analysis (PDA), Management

Posted Date: February 18th, 2021

DOI: https://doi.org/10.21203/rs.3.rs-193825/v1

License: (c) (1) This work is licensed under a Creative Commons Attribution 4.0 International License.

Read Full License 


\section{Author names and affiliations}

4 Weijia Wen ${ }^{1,2}$, Yanhua Zhuang ${ }^{1 *}$, Liang Zhang ${ }^{1}$, Sisi $^{1} i^{1}$, Shuhe Ruan ${ }^{1,2}$, Qinjing Zhang ${ }^{3}$

$5 \quad{ }^{1}$ Hubei Provincial Engineering Research Center of Non-Point Source Pollution Control, Innovation Academy for Precision Measurement Science and Technology, Chinese Academy of Sciences, Wuhan

${ }^{2}$ University of Chinese Academy of Sciences, Beijing 100049, Peoples R China

${ }^{3}$ School of Resource and Environmental Sciences, Wuhan University, Wuhan 430079, Peoples $R$

China

*Yanhua Zhuang 
21

\section{Abbreviations}

Non-point source (NPS); Critical periods (CPs), critical source areas (CSAs), point density analysis (PDA), dual-structure export empirical model (DSEEM); total phosphorus (TP), Danjiangkou Reservoir Basin (DRB).

\section{Abstract}

Non-point source (NPS) pollution has wide range of sources. Under rainfall conditions, NPS pollution occurs mainly by overland flow, resulting in difficult governance. In this study, based on the cooperative analysis of critical periods (CPs) and critical source areas (CSAs), a preferred hierarchical control strategy of NPS pollution, which was connected with management units, was proposed in the Danjiangkou Reservoir Basin (DRB) to improve the pertinence of NPS pollution control. The practicality of the grid-based CSA identification results was improved by point density analysis (PDA). CPs, subCPs, and non-CPs were identified on the temporal scale; CSAs, sub-CSAs and non-CSAs were identified on the spatial scale. The results showed that CPs (July, April, and September), sub-CPs (May, March, and August), and non-CPs contributed $62.8 \%, 31.1 \%$, and $6.1 \%$ of the annual TP loads, respectively. Furthermore, we proposed a hierarchical NPS pollution control strategy: class I (CSAs in CPs) $\rightarrow$ class II (sub-CSAs in CPs, CSAs in sub-CPs) $\rightarrow$ class III (non-CPs, non-CSAs, sub- and non-CSAs in subCPs). Class I covered the periods and areas with the highest NPS pollution loads, contributing $26.2 \%$ of the annual load within $14.5 \%$ of the area and $25.0 \%$ of the time. This study provides a reference for the targeted control of NPS pollution at regional scale, especially in environmental protection with limited 
funds.

42

43 Keywords: Non-point source (NPS) pollution; Critical periods (CPs); Critical source areas (CSAs);

44 Dual-structure export empirical model; Point density analysis (PDA); Management 


\section{Introduction}

Non-point source (NPS) pollution is an important source of river and lake eutrophication and is a major factor deteriorating water quality (Le et al. 2010, Ongley et al. 2010, Vander Zanden et al. 2005, Xue et al. 2020). Impacted by topography, land-use, precipitation, vegetation coverage, and other factors, NPS pollution has great spatiotemporal heterogeneity (Yu et al. 2011). Under rainfall conditions, NPS pollution occurs mainly by overland flow, resulting in difficult governance and low efficiency(Tian et al. 2010). Critical source areas (CSAs) and critical periods (CPs) generate disproportionately high pollutant loads of NPS pollution (Bannerman et al. 1993, Sharpley et al. 1993, Zhang et al. 2019). Studies have shown that more than $50 \%$ of the load is generated from CPs, accounting for $25 \%$ of the time (Ruan et al. 2020), and more than $50 \%$ of the load is generated form CSAs, accounting for less than $30 \%$ of the area (Gburek \&Sharpley 1998, Liu et al. 2016b, Zhuang et al. 2016). Therefore, it is important to identify, target, and remediate the CPs and CSAs to effectively control NPS pollution with limited funds.

The proper identification of CSAs and CPs is crucial. First, model selection affects the precision of identification results and the economic viability of best management practices (BMPs) (Shrestha et al. 2021). In recent years, methods have been proposed for the identification of CSAs along with the development of the NPS pollution model. The export coefficient method is effective in load simulation of large watersheds. However, ignoring the spatiotemporal variation of factors such as runoff and vegetation interception leads to a deviation in CSA distribution (Ding et al. 2010, Johnes 1996, Wang et al. 2020). The mechanistic models (e.g., soil and water assessment tool), which can simulate the characteristics of pollutant transport, can reflect the actual distribution of CPs and CSAs. However, large amounts of high-quality data are required for model calibration and verification (Hao et al. 2004, Panagopoulos et al. 2011, Soranno et al. 1996). The dual-structure export empirical model (DSEEM) 
simulates pollutant loads in particulate and dissolved states respectively; that is, it has the advantage of a model that accurately describes the process of nitrogen and phosphorus loss and requires fewer data (Shi et al. 2002, Wang et al. 2012). Second, the selection of identification methods affects the objectivity of the results. Some methods, such as the pollution index method (e.g., the P Index), which is a simple and wildly used approach, are often conducted subjectively based on expert recommendations without uniform standards (Drewry et al. 2011, Kaplowitz \&Lupi 2012, Lemunyon \&Gilbert 1993, Nelson \&Shober 2012, Sharpley et al. 2003). Third, differences in the spatial scale affect the identification accuracy of CSA. For large-scale watersheds, most CSAs are identified through sub-catchment units, which is an efficient approach for the identification of CSAs; however, it neglects the heterogeneity of NPS pollution load distribution in sub-catchments (Liu et al. 2016b, Niraula et al. 2013, Pradhanang \&Briggs 2014, Ruan et al. 2020, Wang et al. 2018). Considering that administrative units (such as a county) or farms, which are distinct and disconnected with hydrological units, are used for management in most situations (Ghebremichael et al. 2013, Li et al. 2017, Shen et al. 2020), it is difficult to achieve accurate prevention and control of NPS pollution and to effectively allocate BMPs. For small watersheds, CSAs are mostly identified by grids (Zhuang et al. 2016). Grid-based identification can reveal the relationship between the spatial distribution of pollutant load and regional characteristics (topography, land use type, rainfall, etc.). However, the discrete distribution of some CSAs may lead to poor guidance the results.

In this study, the Danjiangkou Reservoir Basin (DRB), an important water source for the MiddleRoute of the South-to-North Water Diversion Project of China (Nong et al. 2020), is selected as the study region to propose a preferred hierarchical NPS pollution control strategy of spatiotemporal pertinence. The main objectives of this study are to (1) simulate the spatiotemporal distribution of the total 
phosphorus (TP) load based on the DSEEM at a monthly scale; (2) conduct a cooperative analysis of the CPs and CSAs; (3) extract CSAs with more realistic guiding importance by point density analysis (PDA); and (4) propose a hierarchical control strategy for NPS pollution.

\section{Materials and Methods}

\subsection{Study area and environmental database}

The DRB $\left(109^{\circ} 29^{\prime}-111^{\circ} 53^{\prime} \mathrm{E}, 32^{\circ} 14^{\prime}-33^{\circ} 48^{\prime} \mathrm{N}\right)$ is located in the middle and upper reaches of the Hanjiang River Basin at the junction of Hubei and Henan provinces (Fig. 1). The total area is approximately 17,924 km², including Danjiangkou City, Shiyan City, Xichuan County, Yunxi County, Yunxian County, and Xixia County. The altitude of the DRB is $17-2125 \mathrm{~m}$, and the overall terrain is high in the northwest and low in the southeast (Fig. 1c). The topography is dominated by hills and mountains, accounting for approximately $97 \%$ of the area (Huang et al. 2012). The average annual rainfall of 800 $1000 \mathrm{~mm}$ is distributed unevenly, mainly from June to September, with rainfall in July accounting for approximately $20 \%$ of the total annual rainfall.

[Insert Fig. 1 here]

Phosphorus is a limiting factor for water quality in the DRB (Chen et al. 2015). Soil erosion, carrying large amounts of phosphorus in the sediment, is an important factor causing NPS pollution and affecting the water quality of the DRB (Huang et al. 2017, Jiang et al. 2020). Characteristics including steep slopes, time variation of normalized difference vegetation index (NDVI) and rainfall causes a clear spatiotemporal heterogeneity of NPS pollution in this area. (Wang et al. 2020). In addition, agricultural NPS pollution is an important source of water pollution in this area (Huang et al. 2012) due to frequent agricultural activities (mainly farming) a and the overuse of chemical fertilizers and pesticides (Jiang et 


\subsection{Simulation of NPS pollution loads} 2010, Shi et al. 2002).

\subsubsection{Particulate pollutant load}

The particulate pollutant load is calculated as:

$$
L_{s}=\alpha \cdot \eta \cdot A \cdot C_{s} \cdot S_{d}
$$

where $L_{s}$ is the particulate pollutant load ( $\mathrm{kg} / \mathrm{ha} /$ month), $\alpha$ is the transformation coefficient $(\mathrm{kg} / \mathrm{t}), A$ is the soil erosion (t/ha/month), $\eta$ is the enrichment ratio of the soil pollutant (dimensionless), $C_{s}$ is the concentration of particulate phosphorus in soil particles (\%), and $S_{d}$ is the sediment transport ratio (dimensionless). The values of each parameter in the formula were determined based on the background data of the study area and previous studies (Shen et al. 2010, Zhuang et al. 2016). $A$ is calculated using MUSLE model:

$$
A=R \cdot L S \cdot K \cdot C \cdot P
$$

where $A$ is the monthly soil erosion amount (t/ha/month), $R$ is the rainfall erosivity factor $(\mathrm{MJ} \cdot \mathrm{mm} / \mathrm{ha} / \mathrm{h} / \mathrm{month}), L S$ is the slope factor of slope length (dimensionless), $K$ is the soil erosion factor conservation measurement factor (dimensionless). 


$$
L_{d}=\beta \cdot C_{d} \cdot Q
$$

where $L_{d}$ is the dissolved phosphorus load of ground types $(\mathrm{kg} / \mathrm{ha}), \beta$ is the conversion coefficient, $C_{d}$ is the concentration of pollutants $(\mathrm{mg} / \mathrm{L})$, and $Q$ is runoff depth $(\mathrm{mm})$. 2010). $Q$ is determined using the Soil Conservation Service model: where $Q$ is the runoff depth (mm), $P$ is the rainfall (mm), $S$ is the maximum infiltration (mm), and $C N$ is the number of curves (dimensionless).

\subsection{Identification of CPs and CSAs}

\subsubsection{Cumulative load-time/area curve fitting} temporal variability of NPS pollution was greater than the spatial variability in the study area. First, the 


$$
T_{j}=\sum_{i=1}^{j} t_{i}
$$

where $L_{j}$ is the cumulative TP load under load grade $j$ in a month (t), $l_{i}$ is the TP load of the $i t h$ month (t), $T_{j}$ is the cumulative number of months under load grade $j$, and $t_{i}$ is the number of months.

The cumulative percentage of TP load $\left(P l_{j}\right)$ and the corresponding cumulative percentage of time $\left(P t_{j}\right)$ were calculated as:

$$
\begin{aligned}
& P l_{j}=\frac{L_{j}}{L_{\text {total }}} \times 100 \% \\
& P t_{j}=\frac{T_{j}}{T_{\text {total }}} \times 100 \%
\end{aligned}
$$

where $L_{\text {total }}$ is the annual total TP load of the study area (t) and $T_{\text {total }}$ is the total number of months.

The cumulative load-time curve was fitted by taking $P l_{j}$ as the ordinate and $P t_{j}$ as the abscissa, with $f$ as the fitting function:

$$
P l_{j}=f\left(P t_{j}\right)
$$

CSAs were similarly identified. The dataset $\left(l_{l}, \ldots l_{i}, \ldots l_{n}\right)$ was generated by arranging the TP load of each grid in a descending order, where $l_{l}$ is the maximum and $l_{n}$ is the minimum value. The relevant parameters were calculated as:

$$
P a_{j}=\frac{A_{j}}{A_{\text {total }}} \times 100 \%
$$

where $P a_{j}$ is the cumulative percentage of grids under load grade $j, A_{j}$ is the cumulative number of grids, and $A_{\text {total }}$ is the total number of grids.

The cumulative load-area curve was fitted as:

$$
P l_{j}=f\left(P a_{j}\right)
$$

where $f$ is the fitting function.

\subsubsection{Criterion selection of CPs and CSAs}



relationship between the growth rate of the TP load and time. When $k_{t}>1$, the load grows faster than time, implying that when the time increment is $1 \%$, the load increment is greater than $1 \%$. Here, the value of $k_{t}$ is 1 as the index to divide the CPs and sub-CPs of phosphorus loss, and the value of $k_{t}$ is 0.5 as the index to divide the sub-CPs and non-CPs. For the load-area curve, $k_{a}$ values represent the growth rate of the TP load along the area. Combined with the concentration of the load in the study area, regions with $k_{a}$ values greater than 2 were divided into CSAs, those with $k_{a}$ values greater than 2 and less than 1 were divided into sub-CSAs, and those with $k^{\prime}$ values less than 1 were divided into non-CSAs. In addition, the CSAs in the CPs, sub-CPs, and the non-CPs were identified to compare the load contribution of CSAs during different periods. $k_{t}$ and $k_{a}$ values were calculated as: extraction of high-density areas as CSAs that required critical control. Thus, CSAs too discrete to control 

dryland CSAs), and few areas between them, were also divided into the final CSAs. In addition, by combining the distribution of slope and land-use types in the study area, few CSAs that are remote, difficult to reach, and small in size were screened to improve the practicality of the identification results.

\section{Results and Discussion}

\subsection{Accuracy verification}

(1) TP load

The annual total TP loads in the DRB (excluding Shiyan City) in 2010 were $0.29 \times 10^{4} \mathrm{t} / \mathrm{a}$, and the TP loads of all six counties or cities in the DRB were $0.30 \times 10^{4} \mathrm{t} / \mathrm{a}$. In 2010, the annual TP loads of the DRB were $0.28 \times 10^{4}$ (excluding Shiyan City) (Jiang et al. 2010) and $0.29 \times 10^{4}$ (the entire study area) (Zhuang et al. 2016). Compared with the results reported by (Jiang et al. 2010), who simulated the TP loads with the equivalent pollution loading method, the relative error was within $10 \%$. This is reasonable because of the differences in the simulation methods. Compared with the study reported by (Zhuang et al. 2016), which simulated TP loads using DSEEM on an annual scale, the relative error was within 5\%. The difference between the results can be attributed to the time variation of NDVI after improving the time resolution of the simulation. The relative error indicates the reliability of the simulation results.

(2) Load-time/area curve

The parameters of the fitting curves were presented, including the load-time curve, load-area curve in CPs, load-area curve in sub-CPs, and load-area curve in non-CPs. The R-square values of the four fitting curves were all greater than 0.94 , indicating that a good fit (Table 2).

[Insert Table 2 here]

(3) CSAs after PDA 
of the CSAs before and after PDA were compared. The results showed that the distribution of CSAs and sub-CSAs became more concentrated after PDA (Fig. 5). The area proportion of CSAs and sub-CSAs increased by $36.0 \%$ and $29.9 \%$ respectively, because non-CSA grids in regions with high CSA aggregation were also considered when identifying CSAs. CSAs after PDA accounted for up to 26.2\% of the annual load with $14.5 \%$ area, and the load/area value was 1.81 , which was important for the control of NPS pollution in the entire region.

\subsection{Spatiotemporal distribution characteristics of TP load}

The TP load in the DRB showed significant spatiotemporal heterogeneities (Fig. 6). The variation and distribution of the TP load in the reservoir area are consistent with rainfall and NDVI, respectively

(Fig. 3 and Fig. 4 in the Appendix). The monthly total TP loads ranged from high to low in July, April, September, May, March, August, June, October, February, November, December, and January. The total shrubland around the DRB. In May, due to the variation in NDVI, the TP load was concentrated in the middle of the reservoir. During high rainfall (August and September), areas around the reservoir, which 
were dominated by forest, had high vegetation coverage. Areas with high TP loads were mainly concentrated in farmland and shrubland in the middle of the reservoir, and the distribution was consistent with the slope (Fig. $2 \mathrm{~b}$ in the Appendix). Therefore, rainfall and vegetation coverage are the most important factors that impact the seasonal distribution of TP loads.

[Insert Fig. 6 here]

\subsection{Cooperative analysis of CPs and CSAs}

\subsubsection{Fitted curve of CPs}

CPs were identified quantitatively using the fitted cumulative load-periods curve (Fig. 9a). The slope $k$ of the fitting curve represents the increasing load rate with periods. The load changes heterogeneously as the area grows. When $k$ was $1,27.9 \%$ of the time contributed $70.8 \%$ of the load. Therefore, we identified July, April, and September as the CPs of the TP NPS pollution in the DRB in 2010, which contributed $62.9 \%$ of the annual TP load with a $25.0 \%$ proportion of the period. In addition, when $k$ was $0.5,55.8 \%$ of the time contributed $90.1 \%$ of the load. May, March, and August were identified as sub-CPs, accounting for $31.0 \%$ TP load with $25.0 \%$ proportion of the period, and the remaining months (June, October, February, November, December, and January) were identified as nonCPs, accounting for $6.1 \%$ of the TP load with $50.0 \%$ proportion of the period.

\subsubsection{Fitted curve of CSAs in CPs}

CSAs during the different periods ( $\mathrm{CP}$, sub-CP, and non- $\mathrm{CP})$ were confirmed based on the TP loads and the identified CPs (Fig. 9b; 9c; 9d). The uneven increase in the $k$ 'value indicates the heterogeneity of the spatial distribution of TP loads. Compared with the load distribution in sub-CPs and non-CPs, the 
load distribution in CPs was more concentrated (the slope of the fitting curve is steeper and the rate of change is faster).

Considering the spatial distribution characteristics of the TP load in the study area, the slope of the fitting curve of 2 was used as the boundary to divide the CSAs and sub-CSAs, and the slope of the fitting curve of 1 was used as the boundary to divide sub-CSAs and non-CSAs. For CPs, when $k^{\prime}$ was 2, the corresponding critical value of TP load was $2.72 \mathrm{~kg} / \mathrm{ha}$, and $10.7 \%$ of the areas contributed $31.3 \%$ of the annual TP load. When $k^{\prime}$ was 1 , the corresponding critical value of TP load was $1.35 \mathrm{~kg} / \mathrm{ha}$, and $21.4 \%$ of the area contributed $43.3 \%$ of the load. For sub-CSAs, when $k^{\prime}$ was $2,11.2 \%$ of the area contributed $13.6 \%$ of the annual load, when $k^{\prime}$ was $1,22.4 \%$ of the area contributed $18.9 \%$ of annual TP load. For non-CPs, 9.5\% of the area within CSAs contributed $3.5 \%$ of the annual load, and $19.1 \%$ of the area in sub-CSAs contributed $4.6 \%$ of the annual load.

[Insert Fig. 9 here]

\subsection{Spatiotemporal distribution characteristics of CSAs}

The spatial distribution of CSAs varied during different periods due to the spatiotemporal changes in rainfall and vegetation coverage (Fig. 3 and Fig. 4 in the Appendix; Fig. 10). According to previous studies, Xichuan and Yunxian counties are the most polluted in the DRB (Jiang et al. 2010), which is consistent with our results. During the CPs, the CSAs were concentrated in the middle and west of the reservoir area, mainly in Xichuan and Yunxian counties (Fig. 10; Fig. 11a), contributing 20.0\% of the annual TP load. During sub-CPs, in addition to Yunxian and Xichuan County, Yunxi counties, which is located in the western part of the DRB, also had a large area of CSA clusters, contributing $1.7 \%$ of the annual TP load. CSAs in non-CPs shifted toward the south and were mainly distributed in the central part 
of Yunxian County and the south-central part of Yunxi County.

[Insert Fig. 10 here]

The results showed that farmland, shrubland, and forest were the main sources of phosphorus in the region, contributing up to $91.7 \%$ of the annual TP load (Fig. 11b). Of the total TP load, $62.3 \%$ originates from the CP, and $23.8 \%$ of the load originates from the CSA during the CP. Approximately $94.2 \%$ of farmland was dry land, with $42.9 \%$ located in an area with a slope of $5-15^{\circ}$ and $18.7 \%$ with a slope greater than $15^{\circ}$. In the TP load contributed by farmland, $63.4 \%$ of the load was generated during CPs (mainly in July) when rainfall was high and extensive amount of fertilizer was used (Huang et al. 2012). These conditions aggravated the soil erosion of farmland and resulted in high phosphorus NPS pollution. For shrubland and forest, $63.4 \%$ and $59.1 \%$ of TP loads originated from CPs, respectively. During CPs, low vegetation coverage in these areas causes high soil erosion risk and high TP loss risk (Sun et al. 2008). In addition, the low vegetation coverage of grasslands in the central part of Xichuan County (Zhuang et al. 2016) also resulted in a high TP concentration of grassland in CPs.

[Insert Fig. 11 here]

\subsection{Preferred hierarchical control strategies for NPS}

Prior to causing NPS pollution, nutrients are impacted by processes such as vegetation interception, river sedimentation, and water self-purification (Frankenberger et al. 2015). Therefore, all NPS sources do not need to be controlled effectively. Periods and areas that generate disproportionately high pollutant loads, were prioritized using the cooperative analysis of CPs and CSAs. For this, a preferred hierarchical control strategy was proposed to achieve efficient short-term and small-scale prevention and control of NPS pollution. Three levels were classified according to the concentration of TP loads: class I (CSAs in 
CSAs in sub-CPs) (Table 3).

[Insert Table 3 here]

Class I (CSA in CP) contributed $26.2 \%$ of the annual load, accounting for $14.5 \%$ of the area and

$25.0 \%$ of the time. The farmland distributed in the slope fields of the central and northeastern parts of

Yunxian County and the northern part of Xichuan County are the main sources of phosphorus NPS

pollution. The poor retention and water conservation capacity of dryland (Fu et al. 2006) combined with

the impact of intense rainfall, steep slopes, and fertilizer overuse (Huang et al. 2012), caused the high

soil loss risk of farmland during this period. For slope farmland under the eco-compensation policy,

measures can be taken to return farmland to forest and grassland to reduce runoff and control soil erosion

(Tang et al. 2011). Hedgerows can be constructed in farmland with a relatively gentle slope. In addition,

replacing traditional fertilization with slow-controlled fertilization and combined application of organic

and inorganic fertilizers (Liu et al. 2016a) can greatly reduce the loss of fertilizer at the early stage of

crop growth. In addition to shrubland and forest, the grassland distribution in the central part of Xichuan interception. 
areas are close to the water bodies, a vegetation buffer zone can be constructed. Furthermore, because agriculture is the most important pollution source in the hydro-fluctuation belt of DRB, and agricultural irrigation affects water quality, water-saving irrigation measures can be taken to mitigate phosphorus loss (Pan et al. 2020, Zhuang et al. 2019). Shrubland and forest generated 10.0\% of the annual TP load during this period when rainfall decreased significantly, and NDVI was the main factor affecting CSA distribution (Fig. 4d, e, and $\mathrm{i}$ in the Appendix). CSAs are distributed more discretely in the shrubland and forest areas in the western, central, and southern parts of the reservoir. In these areas, planting shrubs or trees of different types and different phenological cycles can be considered to improve the stability of the ecosystem.

Class III (non-CP, non-CSA, sub- and non-CSA in sub-CP) contributed $49.8 \%$ of the TP load within $100.0 \%$ of the area and $100.0 \%$ of the time. The distribution of this part of the load shows extremely high spatiotemporal discreteness. Due to the self-purification ability (Cook et al. 2020, He et al. 2020) of the water bodies, extensive human and material resources are not required to control this pollutant load.

\section{Conclusions}

In this study, based on the cooperative analysis of CPs and CSAs and the PDA, a preferred hierarchical control strategy of NPS pollution connected with management units was proposed in the DRB: class I $($ CSAs in CPs) $\rightarrow$ class II (sub-CSAs in CPs, CSAs in sub-CPs) $\rightarrow$ class III (non-CPs, non-CSAs, suband non-CSAs in sub-CPs). The results showed that class I covered the periods and areas with the highest NPS pollution loads, contributed $26.2 \%$ of the annual TP load within $25.0 \%$ of the time and $14.5 \%$ of the area. The farmland distributed in the slope fields of the central and northeastern parts of Yunxian County and the northern part of Xichuan County were the main sources of phosphorus NPS pollution. Conversion 
of farmland to forest, hedgerow, and reasonable fertilization regimes were advocated to mitigate NPS pollution; class II contributed $24.0 \%$ of the TP load within $24.8 \%$ of the area and $50.0 \%$ of the time, with sub-CSA in CP contributing $13.1 \%$ of the TP load within $13.9 \%$ of the area and $25.0 \%$ of the time and CSA in sub-CP contributing $10.9 \%$ of the TP load within $14.1 \%$ of the area and $25.0 \%$ of the time. Considering that most CSAs are distributed on slope farmland near water bodies, a vegetation buffer zone could be constructed; class III contributed $49.8 \%$ of the TP load within $100.0 \%$ of the area and $100.0 \%$ of the time. Extensive human and material resources were not required to control this pollutant load. This study provides a reference for the targeted control of NPS pollution at regional scale, especially in environmental protection with limited funds.

\section{Declarations}

Ethics approval and consent to participate: Not applicable.

Consent for publication: Not applicable.

Availability of data and materials: The datasets generated and/or analyzed during the current study are available in the repositories: China Soil Scientific Database (http://www.soil.csdb.cn/); Geospatial Data Cloud (http://www.gscloud.cn); Landsat 7 ETM Data (https://earthexplorer.usgs.gov/); China Meteorology Data Service Center (http://data.cma.cn).

Competing interests: The authors declare that they have no competing interests. 
Funding: This work was supported by the Strategic Priority Research Program of the Chinese Academy of Sciences [No. XDA23040403], the Hubei Technological Innovation Special Fund of China [Nos. 2018ACA148 and 2019ACA155], and the Youth Innovation Promotion Association, CAS [No. 2018370].

Authors' contributions: Conceptualization: Yanhua Zhuang; Methodology: Yanhua Zhuang, Weijia Wen;

Formal analysis and investigation: Yanhua Zhuang; Writing - original draft preparation: Weijia Wen;

Writing - review and editing: Yanhua Zhuang, Liang Zhang, Sisi Li, Shuhe Ruan; Funding acquisition:

Yanhua Zhuang, Liang Zhang; Resources: Weijia Wen, Shuhe Ruan, Qinjing Zhang; Supervision: Yanhua

Zhuang.

\section{References}

Bannerman RT, Owens DW, Dodds RB, Hornewer NJ (1993) Sources of pollutants in Wisconsin stormwater. Water Sci Technol 28: 241-259. doi: 10.3321/j.issn:0253-2468.2002.04.012

Chen P, Li L, Zhang HB (2015) Spatio-temporal variations and source apportionment of water pollution in Danjiangkou Reservoir Basin, central China. Water 7: 2591-2611. doi: 10.3390/w7062591

Cook S, Price O, King A, Finnegan C, Bending GD (2020) Bedform characteristics and biofilm community development interact to modify hyporheic exchange. Sci Total Environ 749: 141397. doi: 10.1016/j.scitotenv.2020.141397

Ding XW, Shen ZY, Hong Q, Yang ZF, Wu X, Liu RM (2010) Development and test of the Export Coefficient Model in the Upper Reach of the Yangtze River. J Hydrol 383: 233-244. doi: 10.1016/j.jhydrol.2009.12.039

Drewry JJ, Newham LH, Greene RSB (2011) Index models to evaluate the risk of phosphorus and nitrogen loss at catchment scales. J Environ Manage 92: 639-649. doi: 10.1016/j.jenvman.2010.10.001

Frankenberger JR, Brooks ES, Walter MT, Walter MF, Steenhuis TS (2015) A GIS-based variable source area hydrology model. Hydrol Process 13: 805-822. doi: 10.1002/(sici)10991085(19990430)13:6\%3c805::aid-hyp754\%3e3.0.co;2-m

Fu GB, Chen SL, McCool DK (2006) Modeling the impacts of no-till practice on soil erosion and sediment yield with RUSLE, SEDD, and ArcView GIS. Soil Tillage Res 85: 38-49. doi: 10.1016/j.still.2004.11.009

Gburek WJ, Sharpley AN (1998) Hydrologic controls on phosphorus loss from upland agricultural watersheds. J Environ Qual 27: 267-277. doi: 10.2134/jeq1998.00472425002700020005x

Ghebremichael LT, Veith TL, Hamlett JM (2013) Integrated watershed- and farm-scale modeling 
framework for targeting critical source areas while maintaining farm economic viability. Journal of environmental management 114: 381-94. doi: 10.1016/j.jenvman.2012.10.034

Hao FH, Zhang XS, Yang ZF (2004) A distributed non-point source pollution model: Calibration and validation in the Yellow River Basin. J Environ Sci 16: 646-650. doi: 10.3321/j.issn:10010742.2004.04.025

He X, Chen G, Fang Z, Liang W, Li B, Tang J, Sun Y, Qin L (2020) Source identification of chromium in the sediments of the Xiaoqing River and Laizhou Bay: A chromium stable isotope perspective. Environ Pollut 264: 114686. doi: 10.1016/j.envpol.2020.114686

Huang Q, Huang J, Yang X, Ren L, Tang C, Zhao L (2017) Evaluating the scale effect of soil erosion using landscape pattern metrics and information entropy: a case study in the Danjiangkou reservoir area, China. Sustainability 9: 1243. doi: 10.3390/su9071243

Huang W, Bi Y, Hu Z, Wang H, Feng R, Hu J (2012) Study on characteristics of agricultural non-point source pollution in Danjiangkou Reservoir. Environ Sci Manage (China) 37: 33-38. doi: 10.3969/j.issn.1673-1212.2012.01.008

Jiang Q, Zhou P, Liao C, Liu Y, Liu F (2020) Spatial pattern of soil erodibility factor (K) as affected by ecological restoration in a typical degraded watershed of central China. Sci Total Environ 749: 141609. doi: 10.1016/j.scitotenv.2020.141609

Jiang S, Han P, Jia Z, Mao X, Si J, Ye F (2010) Evaluation with PSR Model and GIS Analysis of Agricultural Non-point Source Pollution in Danjiangkou Reservoir of the Mid-Route of the South-to-North Water Transfer Project. J Agro-Environ Sci (China) 29: 2153-2162. doi:

Johnes PJ (1996) Evaluation and management of the impact of land use change on the nitrogen and phosphorus load delivered to surface waters: The export coefficient modelling approach. J Hydrol 183: 323-349. doi: Doi 10.1016/0022-1694(95)02951-6

Kaplowitz MD, Lupi F (2012) Stakeholder preferences for best management practices for non-point source pollution and stormwater control. Landsc Urban Plan 104: 364-372. doi: 10.1016/j.landurbplan.2011.11.013

Le C, Zha Y, Li Y, Sun D, Lu H, Yin B (2010) Eutrophication of lake waters in China: cost, causes, and control. Environ Manage 45: 662-8. doi: 10.1007/s00267-010-9440-3

Lemunyon JL, Gilbert RG (1993) The concept and need for a phosphorus assessment-tool. J Prod Agric 6: 483-486. doi: Doi 10.2134/Jpa1993.0483

Li S, Gitau M, Bosch D, Engel BA, Zhang L, Du Y (2017) Development of a soil moisture-based distributed hydrologic model for determining hydrologically based critical source areas. Hydrol Process 31: 3543-3557. doi: 10.1002/hyp.11276

Liu RH, Kang YH, Wan SQ, Pei L (2016a) Evaluation of methods of nutrient and water management on tea performance and nutrient loss in the Danjiangkou Reservoir area, China. Arch Agron Soil Sci 62: 1123-1135. doi: 10.1080/03650340.2015.1115017

Liu RM, Xu F, Zhang PP, Yu WW, Men C (2016b) Identifying non-point source critical source areas based on multi-factors at a basin scale with SWAT. J Hydrol 533: 379-388. doi: 10.1016/j.jhydrol.2015.12.024

Nelson NO, Shober AL (2012) Evaluation of phosphorus indices after twenty years of science and development. J Environ Qual 41: 1703-10. doi: 10.2134/jeq2012.0342

Niraula R, Kalin L, Srivastava P, Anderson CJ (2013) Identifying critical source areas of nonpoint source pollution with SWAT and GWLF. Ecol Model 268: 123-133. doi: 10.1016/j.ecolmodel.2013.08.007 
Nong X, Shao D, Zhong H, Liang J (2020) Evaluation of water quality in the South-to-North Water Diversion Project of China using the water quality index (WQI) method. Water Res 178: 115781. doi: 10.1016/j.watres.2020.115781

Ongley ED, Xiaolan Z, Tao Y (2010) Current status of agricultural and rural non-point source Pollution assessment in China. Environ Pollut 158: 1159-68. doi: 10.1016/j.envpol.2009.10.047

Pan L, Han Y, Wang H (2020) Spatial-temporal variation of nitrogen and diffusion flux across the watersediment interface at the hydro-fluctuation belt of Danjiangkou reservoir in China. Water Sup 20: 1241-1252. doi: 10.2166/ws.2020.044

Panagopoulos Y, Makropoulos C, Baltas E, Mimikou M (2011) SWAT parameterization for the identification of critical diffuse pollution source areas under data limitations. Ecol Model 222: 3500-3512. doi: 10.1016/j.ecolmodel.2011.08.008

Pradhanang SM, Briggs RD (2014) Effects of critical source area on sediment yield and streamflow. Water Environ J 28: 222-232. doi: 10.1111/wej.12028

Ruan S, Zhuang Y, Hong S, Zhang L, Wang Z, Tang X, Wen W (2020) Cooperative identification for critical periods and critical source areas of nonpoint source pollution in a typical watershed in China. Environ Sci Pollut Res 27: 10472-10483. doi: 10.1007/s11356-020-07630-w

Sharpley AN, Daniel TC, Edwards DR (1993) Phosphorus movement in the landscape. J Prod Agric 6: 492-500. doi: 10.2134/Jpa1993.0492

Sharpley AN, Weld JL, Beegle DB, Kleinman PJA, Gburek WJ, Moore PA, Mullins G (2003) Development of phosphorus indices for nutrient management planning strategies in the United States. J Soil Water Conserv 58: 137-152.

Shen H, Zhang W, Peng H (2010) Research on soil erosion and particulate phosphorus load of non-point source pollution in the middle and lower reaches of the Hanjiang River basin. Res Soil Water Conserv (China) 17: 1-6.

Shen W, Zhang L, Li S, Zhuang Y, Liu H, Pan J (2020) A framework for evaluating county-level nonpoint source pollution: Joint use of monitoring and model assessment. Sci Total Environ 722: 137956. doi: 10.1016/j.scitotenv.2020.137956

Shi Z, Cai C, Ding S, LI Z, Wang T, Zhang B, Shen X (2002) Research on nitrogen and phosphorus load of agricultural non-point sources in middle and lower reaches of Hanjiang River besed on GIS. Acta Sci Circumst (China) 22: 473-477.

Shrestha NK, Rudra RP, Daggupati P, Goel PK, Shukla R (2021) A comparative evaluation of the continuous and event-based modelling approaches for identifying critical source areas for sediment and phosphorus losses. J Environ Manage 277: 111427. doi: 10.1016/j.jenvman.2020.111427

Soranno PA, Hubler SL, Carpenter SR, Lathrop RC (1996) Phosphorus loads to surface waters: A simple model to account for spatial pattern of land use. Ecol Appl 6: 865-878. doi: 10.2307/2269490

Sun ZC, Shi ZH, Ng SL, Li L, Li Z, Cai CF (2008): Mapping soil erosion risk in Danjiangkou Reservoir area using RUSLE, RS and GIS: a case study of Danjiangkou City, International Conference on Informational Technology \& Environmental

Tang LH, Yang DW, Hu HP, Gao B (2011) Detecting the effect of land-use change on streamflow, sediment and nutrient losses by distributed hydrological simulation. J Hydrol 409: 172-182. doi: 10.1016/j.jhydrol.2011.08.015

Tian Y, Huang Z, Xiao W (2010) Reductions in non-point source pollution through different management practices for an agricultural watershed in the Three Gorges Reservoir Area. J Environ Sci: 184- 
191. doi: 10.1016/S1001-0742(09)60091-7

Vander Zanden M, Vadeboncoeur Y, Diebel M, Jeppesen E (2005) Primary consumer stable nitrogen isotones as indicators of nutrient source. Environ Sci Technol 39: 7509-7515. doi: $10.1021 / \mathrm{es} 050606 \mathrm{t}$

Wang W, Chen L, Shen Z (2020) Dynamic export coefficient model for evaluating the effects of environmental changes on non-point source pollution. Sci Total Environ 747: 141164. doi: 10.1016/j.scitotenv.2020.141164

Wang X, Wang Q, Wu C, Liang T, Zheng D, Wei X (2012) A method coupled with remote sensing data to evaluate non-point source pollution in the Xin'anjiang catchment of China. Sci Total Environ 430. doi: 10.1016/j.scitotenv.2012.04.052

Wang Y, Yang J, Liang J, Qiang Y, Fang S, Gao M, Fan X, Yang G, Zhang B, Feng Y (2018) Analysis of the environmental behavior of farmers for non-point source pollution control and management in a water source protection area in China. Sci Total Environ 633: 1126-1135. doi: 10.1016/j.scitotenv.2018.03.273

Xue L, Hou P, Zhang Z, Shen M, Liu F, Yang L (2020) Application of systematic strategy for agricultural non-point source pollution control in Yangtze River basin, China. Agric Ecosyst Environ 304: 107148. doi: 10.1016/j.agee.2020.107148

Yu H, Xi B, Jiang J, Heaphy MJ, Wang H, Li D (2011) Environmental heterogeneity analysis, assessment of trophic state and source identification in Chaohu Lake, China. Environ Sci Pollut Res 18: 1333-42. doi: 10.1007/s11356-011-0490-8

Zhang Z, Huang P, Chen ZH, Li JM (2019) Evaluation of distribution properties of non-point source pollution in a subtropical monsoon watershed by a hydrological model with a modified runoff module. Water 11: 993. doi: Artn 99310.3390/W11050993

Zhuang YH, Zhang L, Du Y, Yang WJ, Wang LH, Cai XB (2016) Identification of critical source areas for nonpoint source pollution in the Danjiangkou Reservoir Basin, China. Lake Reserv Manage 32: 341-352. doi: 10.1080/10402381.2016.1204396

Zhuang YH, Zhang L, Li SS, Liu HB, Zhai LM, Zhou F, Ye YS, Ruan SH, Wen WJ (2019) Effects and potential of water-saving irrigation for rice production in China. Agr Water Manage 217: 374382. doi: 10.1016/j.agwat.2019.03.010 
Table 1 Environmental data of DRB

Table 2 Fit and accuracy of cumulative load-time curve and cumulative load-area curve

Table 3 Load and area contribution of different periods and areas and classification of NPS pollution control

\section{Figure captions}

Fig. 1 Location of the DRB: (a) location of the DRB as seen on the Chinese map; (b) location of the DRB in the Yangtze River Basin; and (c) elevation of the DRB

Fig. 2 Spatial distribution of soil erosion in DRB: (a) land-use; (b) slope degree (in the Appendix)

Fig. 3 Monthly rainfall of the 10 weather stations near DRB in 2010 (in the Appendix)

Fig. 4 NDVI of DRB: (a) to (1) represent January to December (in the Appendix)

Fig. 5 Comparison of CSA distribution in CPs before and after PDA: (a) before PDA and (b) after PDA

Fig. 6 Distribution of unit TP load ( $\mathrm{kg} / \mathrm{ha})$ in DRB in 2010: (a) to (l) represent January to December

Fig. 7 Distribution of unit particulate phosphorus (PP) load (kg/ha) in DRB in 2010: (a) to (l) represent January to December (in the Appendix)

Fig. 8 Distribution of unit dissolved phosphorus (DP) load ( $\mathrm{kg} / \mathrm{ha}$ ) in DRB in 2010: (a) to (l) represent January to December (in the Appendix)

Fig. 9 Cumulative load-time fitting curve (a) and cumulative load-area fitting curves (b-d): (a) cumulative load-time curve; (b) cumulative load-area curve of CSAs in CPs; (c) cumulative load-area curve of CSAs in sub-CPs; and (d) cumulative load-area curve of CSAs in non-CPs

Fig.10 Spatial distribution of CSAs during different periods: (a) in CPs; (b) in sub-CPs; and (c) in non- 
Fig. 11 Proportion of TP loads in different periods and areas: (a) within each county and (b) within each

551 land-use type

552 
Table 1 Environmental data of DRB

\begin{tabular}{|c|c|c|c|}
\hline Database & Format & Description & Source \\
\hline Soil type & Vector & $\begin{array}{l}\text { 1:400, } 000 \text { Chinese } \\
\text { soil distribution } \\
\text { vector map }\end{array}$ & $\begin{array}{l}\text { China Soil Scientific Database, } \\
\text { Institute of Soil Science, Chinese } \\
\text { Academy of Sciences } \\
\text { (CAS)(http://www.soil.csdb.cn/) }\end{array}$ \\
\hline DEM & Raster & $\begin{array}{c}\text { 30M resolution } \\
\text { digital elevation } \\
\text { data }\end{array}$ & $\begin{array}{l}\text { Geospatial Data Cloud } \\
\text { (http://www.gscloud.cn) }\end{array}$ \\
\hline Land-use & Raster & $\begin{array}{l}\text { Including forest, } \\
\text { grassland, farmland, } \\
\text { shrubland, } \\
\text { wasteland, } \\
\text { construction land, } \\
\text { orchard and wetland }\end{array}$ & $\begin{array}{l}\text { Interpreted from Landsat } 7 \text { ETM data } \\
\text { (https://earthexplorer.usgs.gov/) }\end{array}$ \\
\hline NDVI & Raster & $\begin{array}{l}\text { Monthly data set, } \\
\text { calculated by } \\
\text { MODND1D }\end{array}$ & $\begin{array}{l}\text { Geospatial Data Cloud } \\
\text { (http://www.gscloud.cn/) }\end{array}$ \\
\hline Rainfall & Excel & $\begin{array}{l}\text { Daily rainfall data } \\
\text { set }(1991 \sim 2010) \text { of } \\
10 \text { weather stations }\end{array}$ & $\begin{array}{l}\text { China Meteorology Data Service } \\
\text { Center (http://data.cma.cn) }\end{array}$ \\
\hline
\end{tabular}


556 Table 2 Fit and accuracy of cumulative load-time curve and cumulative load-area curve

\begin{tabular}{llllll}
\hline \multirow{2}{*}{ Description } & $\mathrm{a}$ & \multicolumn{3}{c}{$\mathrm{b}$} & \multicolumn{2}{c}{$\begin{array}{l}\text { Statistics } \\
R^{2}\end{array}$} \\
\cline { 2 - 5 } & Value & S.E. & Value & S.E. & 0.952 \\
\hline Load-time curve & 27.923 & 1.895 & -22.187 & 7.305 & 0.971 \\
Load-area curve in & 21.356 & 0.003 & 3.910 & 0.010 & 0.953 \\
$\begin{array}{l}\text { CPs } \\
\text { Load-area curve in } \\
\text { sub-CPs }\end{array}$ & 22.430 & 0.004 & -4.268 & 0.013 & 0.962 \\
$\begin{array}{l}\text { Load-area curve in } \\
\text { non-CPs }\end{array}$ & 19.052 & 0.003 & 17.510 & 0.010 & \\
\hline $\begin{array}{l}\text { fitting function: } \mathrm{y}=\mathrm{a} \times \ln (\mathrm{x})+\mathrm{b} \\
\end{array}$ & & & &
\end{tabular}


Table 3 Load and area contribution of different periods and areas and classification of NPS pollution

559 control

\begin{tabular}{|c|c|c|c|c|c|c|}
\hline Descriptions & Month & Region & $\operatorname{Load}\left(\times 10^{4} \mathrm{t}\right)$ & Load (\%) & Area $(\%)$ & Class \\
\hline \multirow{3}{*}{$\mathrm{CP}$} & \multirow{3}{*}{$7,4,9$} & CSA & 0.080 & 26.2 & 14.5 & I \\
\hline & & sub-CSA & 0.040 & 13.1 & 13.9 & II \\
\hline & & non-CSA & 0.071 & 23.5 & 71.6 & III \\
\hline \multirow[t]{2}{*}{ sum } & - & - & 0.191 & 62.8 & 100.0 & - \\
\hline & & CSA & 0.033 & 10.9 & 14.1 & II \\
\hline \multirow[t]{2}{*}{ sub-CP } & $5,3,8$ & sub-CSA & 0.023 & 7.5 & 18.5 & III \\
\hline & & non-CSA & 0.038 & 12.7 & 67.4 & III \\
\hline \multirow[t]{2}{*}{ sum } & - & - & 0.094 & 31.1 & 100.0 & - \\
\hline & 6,10 & CSA & 0.008 & 2.8 & 13.5 & III \\
\hline \multirow[t]{2}{*}{ non-CP } & 2,11 & sub-CSA & 0.005 & 1.5 & 13.8 & III \\
\hline & 12,1 & non-CSA & 0.006 & 1.8 & 72.7 & III \\
\hline sum & - & - & 0.019 & 6.1 & 100.0 & - \\
\hline
\end{tabular}

560

Class is the NPS pollution control level. 
DRB in the Yangtze River Basin; and (c) elevation of the DRB

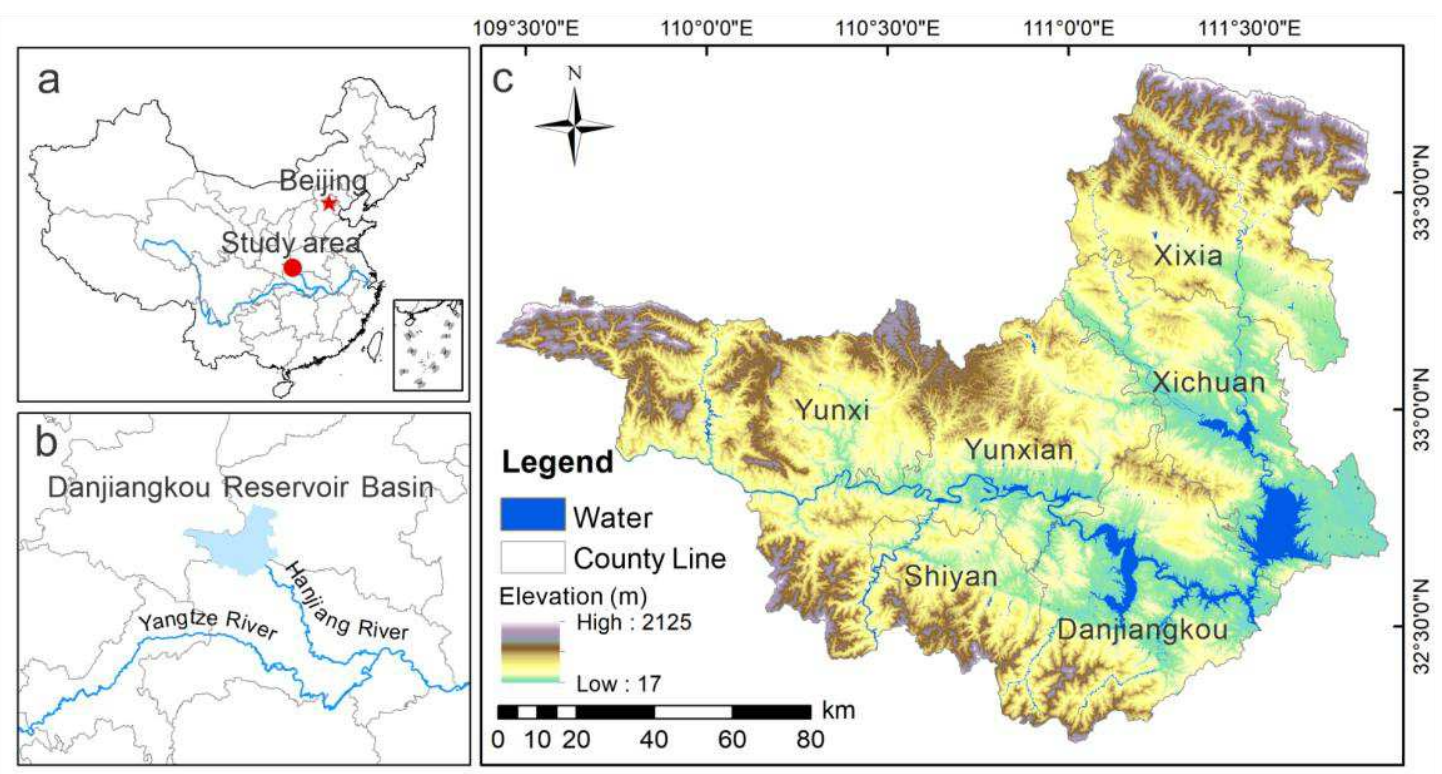


565 Fig. 5 Comparison of CSA distribution in CPs before and after PDA: (a) before PDA and (b) after PDA
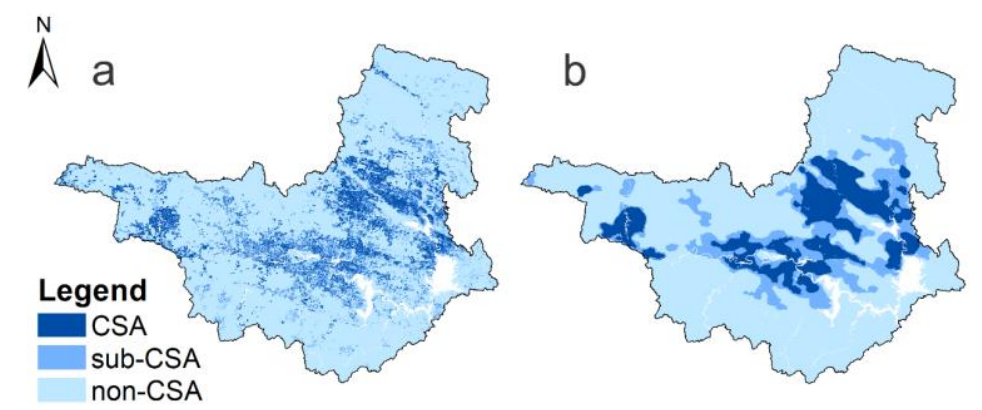

566 

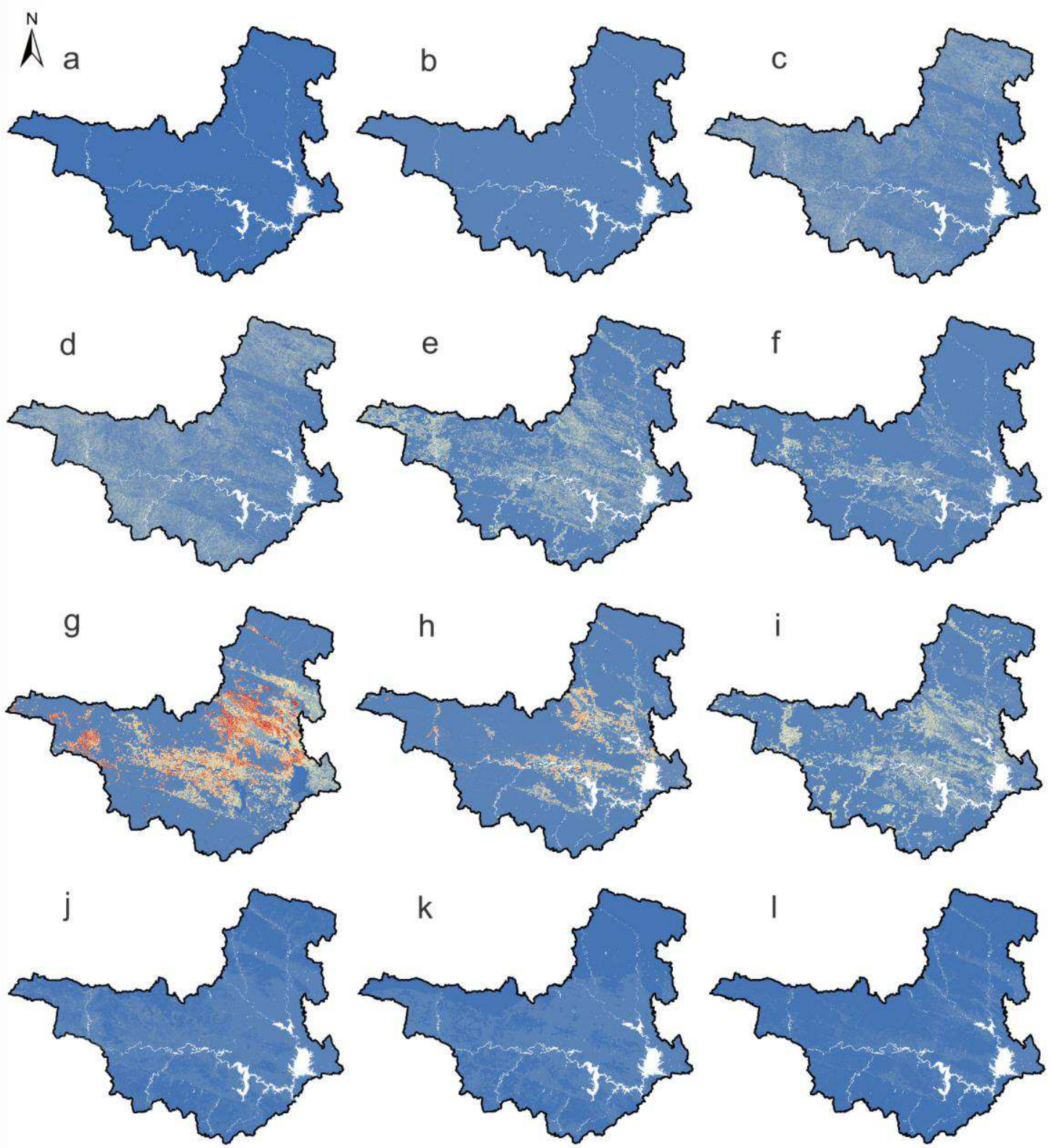

TP loads (kg/ha)

$\begin{array}{lll}0.0 & 14.1 & 28.3\end{array}$ 

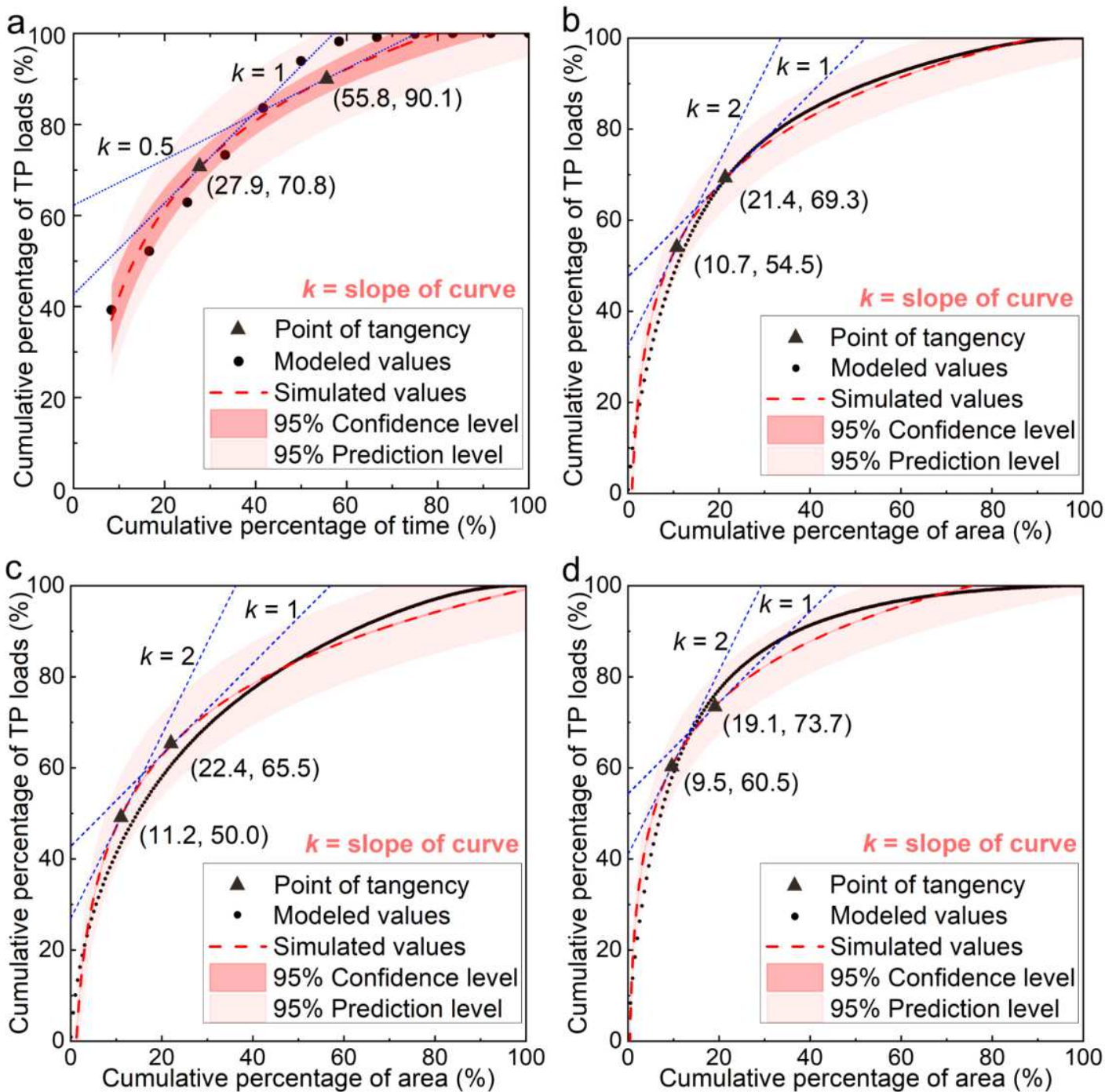
572 Fig. 10 Spatial distribution of CSAs during different periods: (a) in CPs; (b) in sub-CPs; and (c) in non-

573 CPs
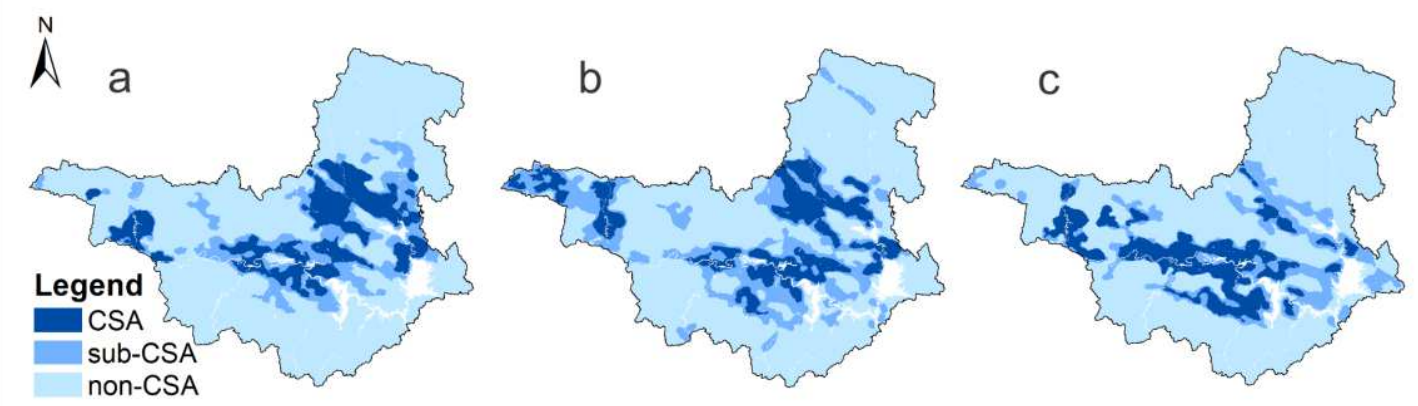
576 land-use type
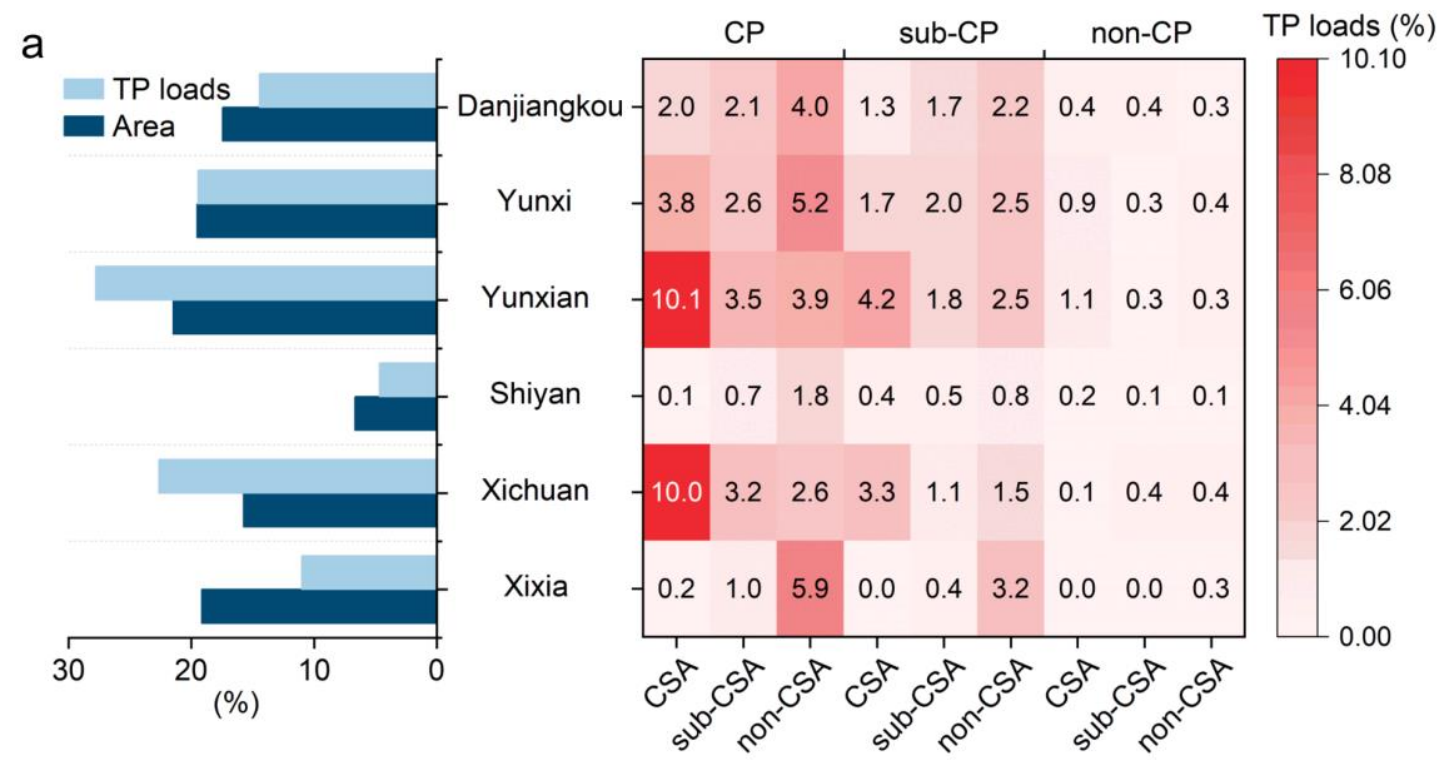

b

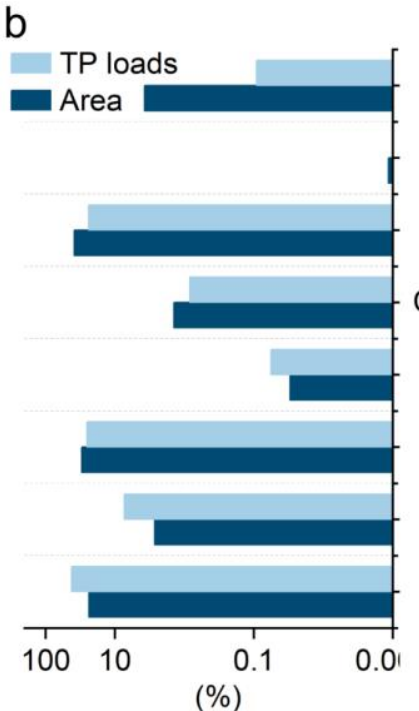

\begin{tabular}{|c|c|c|c|c|c|c|c|c|c|c|}
\hline \multirow[b]{2}{*}{ Wetland } & \multicolumn{3}{|c|}{$\mathrm{CP}$} & \multicolumn{2}{|c|}{ sub-CP } & \multicolumn{4}{|c|}{ non-CP } & \multirow{2}{*}{$\begin{array}{l}\text { TP loads (\%) } \\
11.8\end{array}$} \\
\hline & 0.0 & 0.0 & 0.0 & 0.0 & 0.0 & 0.0 & 0.0 & $6.8 \mathrm{E}-4$ & 0.0 & \\
\hline Orchard & 0.0 & 0.0 & $5.1 \mathrm{E}-4$ & 0.0 & 0.0 & $2.0 \mathrm{E}-4$ & 0.0 & $0.0 \epsilon$ & $6.3 E-5$ & 94 \\
\hline Forest & 2.9 & 1.9 & 9.5 & 1.3 & 1.7 & 5.7 & 0.4 & 0.2 & 0.6 & \\
\hline Construction land & 0.1 & 0.2 & 0.2 & 0.1 & 0.1 & 0.1 & 0.0 & 0.0 & 0.0 & 7.1 \\
\hline Wasteland & 0.0 & 0.0 & 0.0 & 0.0 & 0.0 & 0.0 & $1.6 \mathrm{E}-5$ & 50.0 & 0.0 & 7 \\
\hline Shrubland & 7.2 & 3.1 & 5.9 & 2.8 & 2.1 & 3.1 & 0.7 & 0.3 & 0.5 & \\
\hline Grassland & 4.2 & 0.6 & 0.4 & 1.4 & 0.3 & 0.2 & 0.1 & 0.1 & 0.1 & 2.4 \\
\hline Farmland & 11.8 & 7.4 & 7.6 & 5.2 & 3.3 & 3.6 & 1.6 & 0.9 & 0.7 & \\
\hline
\end{tabular}




\section{Figures}

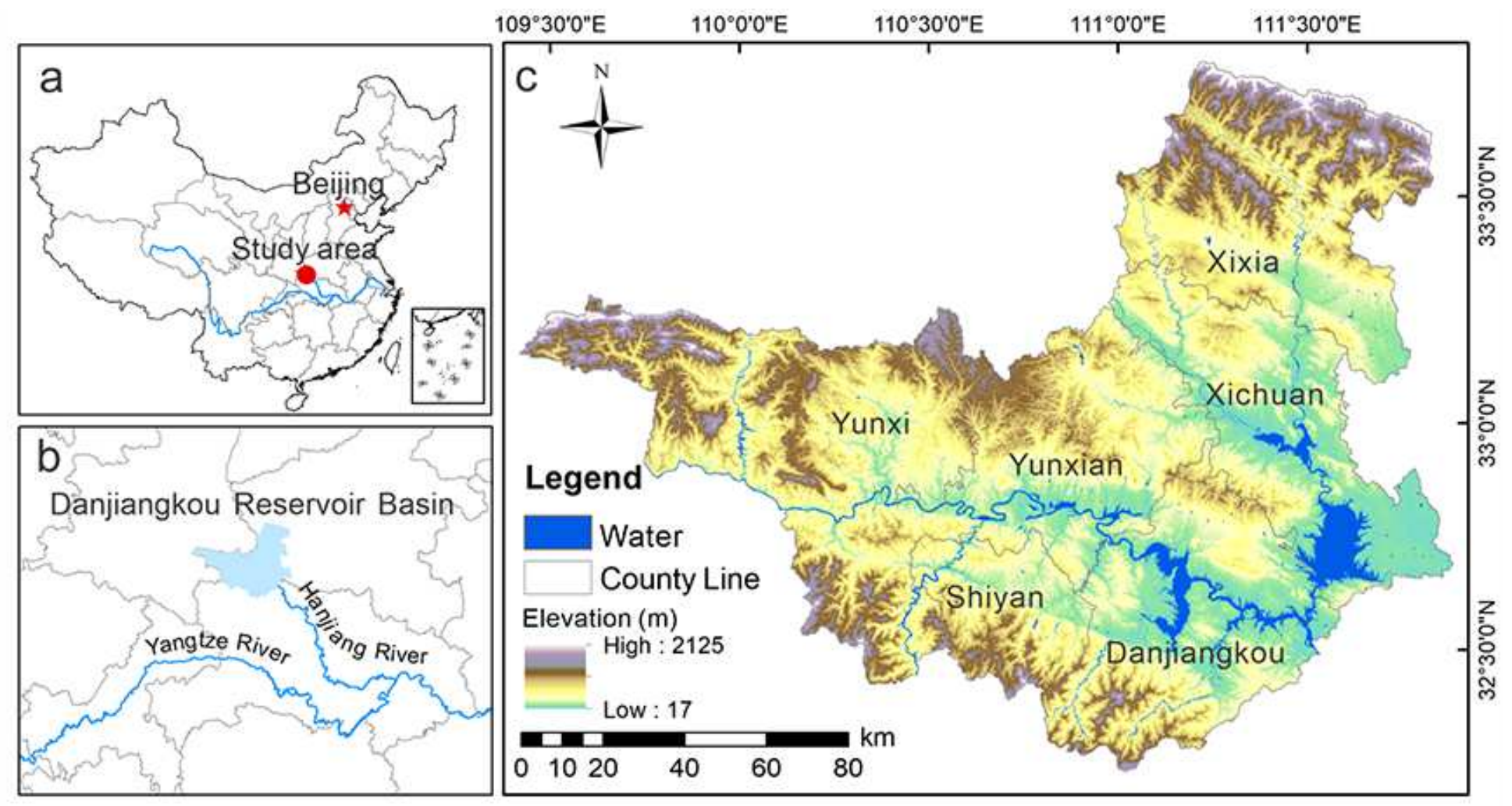

\section{Figure 1}

Location of the DRB: (a) location of the DRB as seen on the Chinese map; (b) location of the DRB in the Yangtze River Basin; and (c) elevation of the DRB Note: The designations employed and the presentation of the material on this map do not imply the expression of any opinion whatsoever on the part of Research Square concerning the legal status of any country, territory, city or area or of its authorities, or concerning the delimitation of its frontiers or boundaries. This map has been provided by the authors.

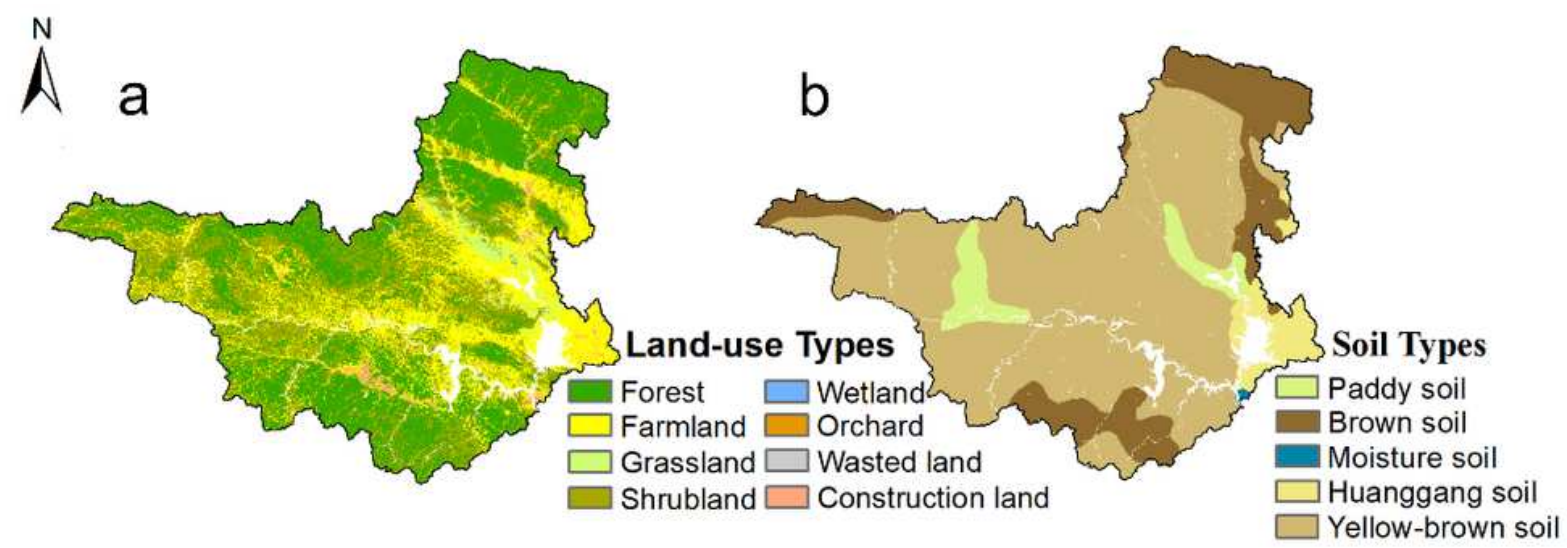

\section{Figure 2}

Spatial distribution of soil erosion in DRB: (a) land-use; (b) slope degree (in the Appendix) Note: The designations employed and the presentation of the material on this map do not imply the expression of 
any opinion whatsoever on the part of Research Square concerning the legal status of any country, territory, city or area or of its authorities, or concerning the delimitation of its frontiers or boundaries. This map has been provided by the authors.

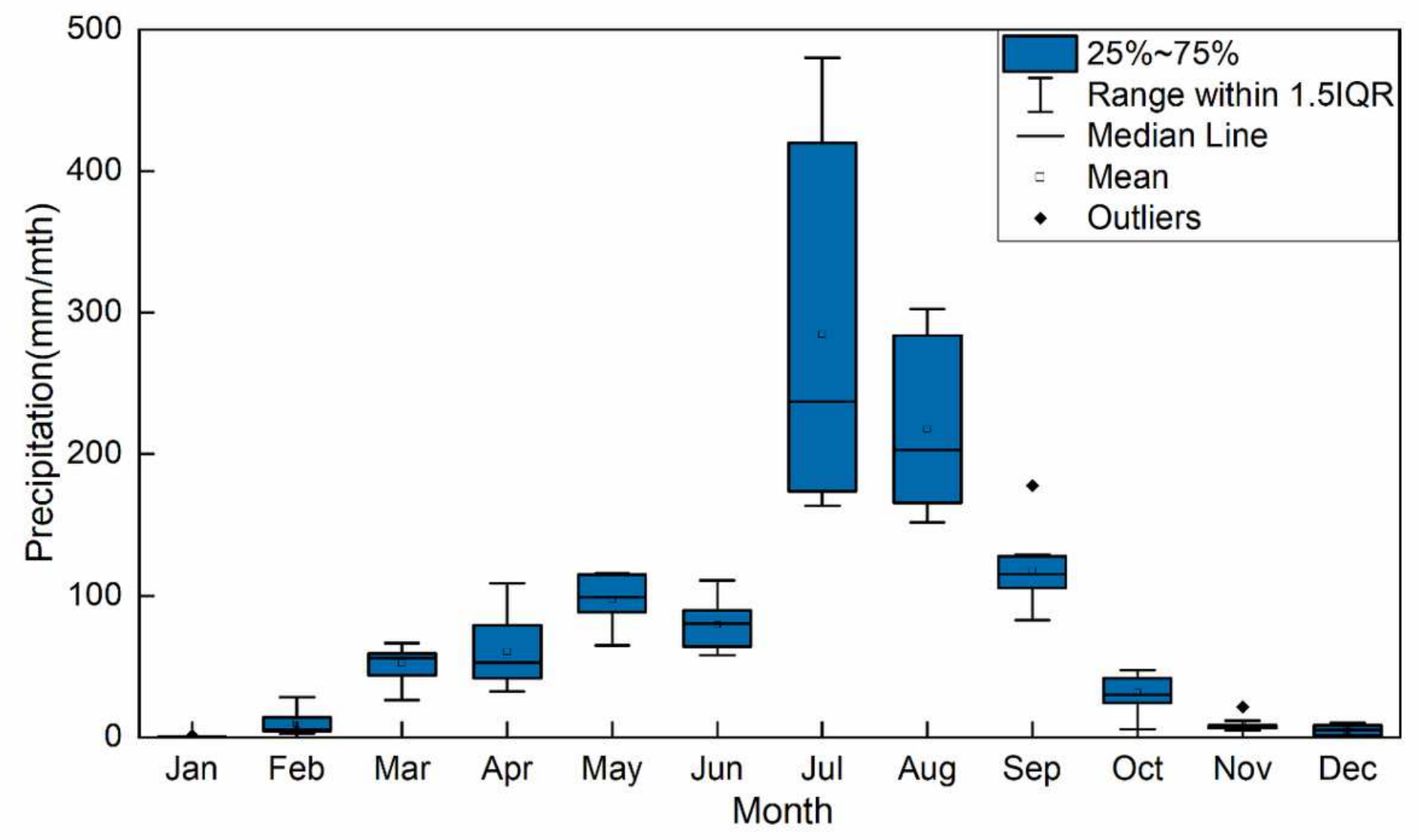

Figure 3

Monthly rainfall of the 10 weather stations near DRB in 2010 (in the Appendix) 

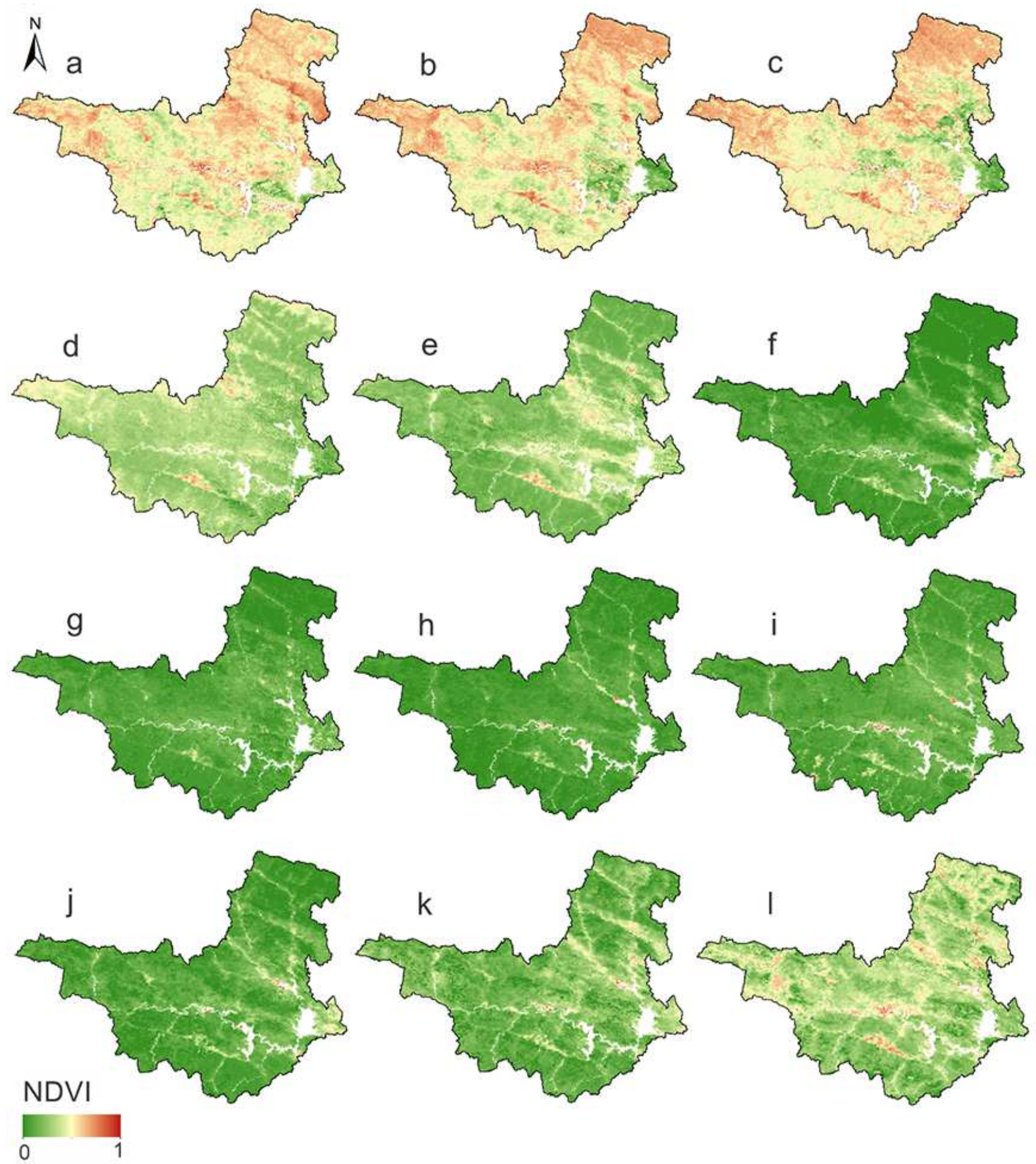

\section{Figure 4}

NDVI of DRB: (a) to (I) represent January to December (in the Appendix) Note: The designations employed and the presentation of the material on this map do not imply the expression of any opinion whatsoever on the part of Research Square concerning the legal status of any country, territory, city or area or of its authorities, or concerning the delimitation of its frontiers or boundaries. This map has been provided by the authors. 


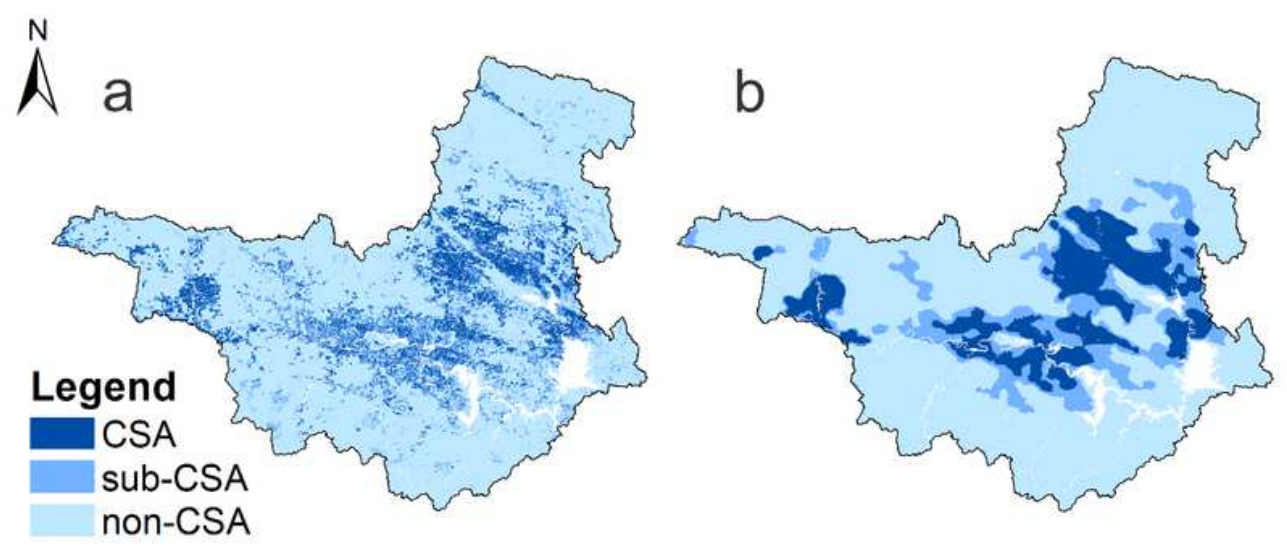

\section{Figure 5}

Comparison of CSA distribution in CPs before and after PDA: (a) before PDA and (b) after PDA Note: The designations employed and the presentation of the material on this map do not imply the expression of any opinion whatsoever on the part of Research Square concerning the legal status of any country, territory, city or area or of its authorities, or concerning the delimitation of its frontiers or boundaries. This map has been provided by the authors. 

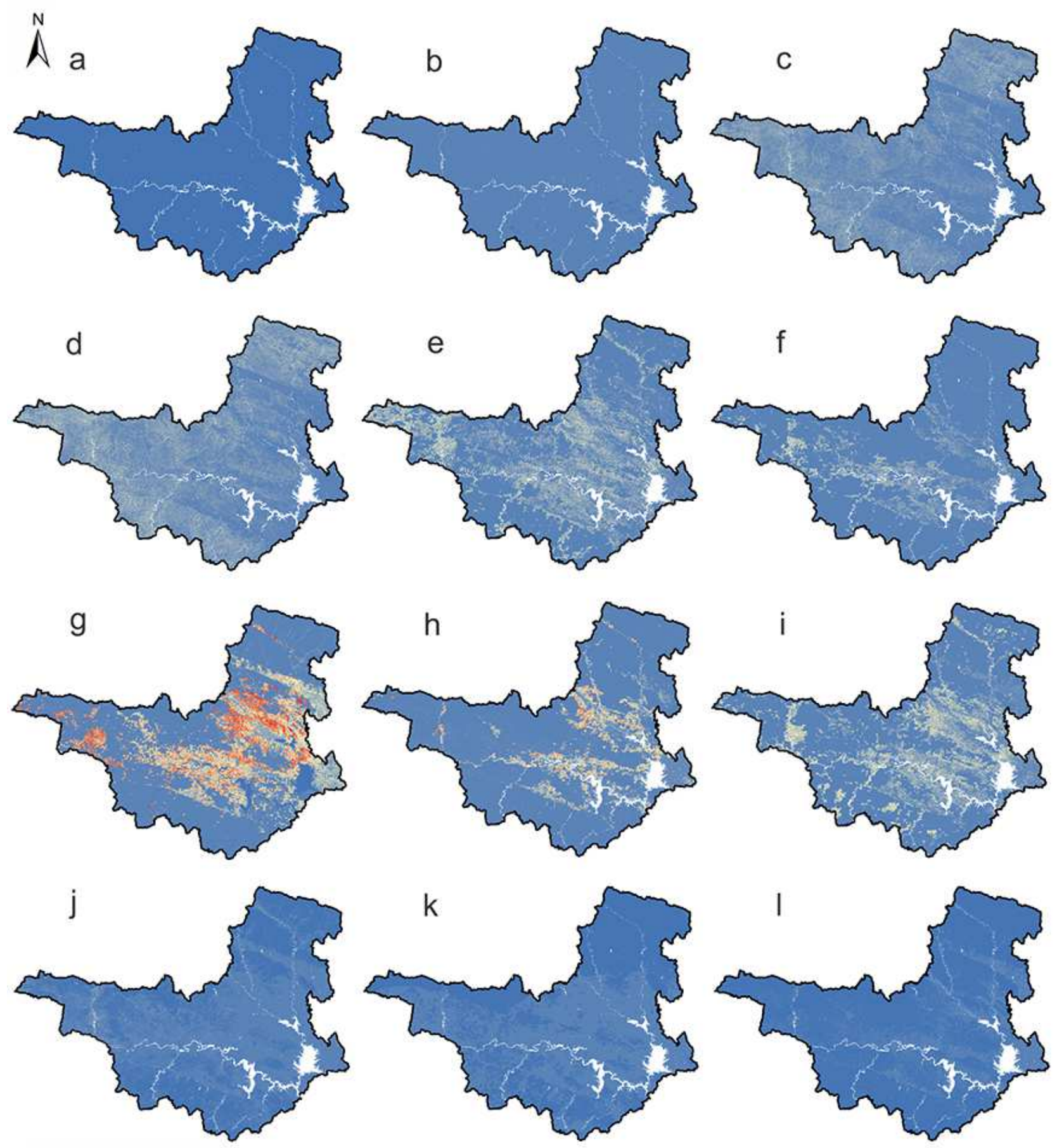

TP loads (kg/ha)

\section{$\begin{array}{lll}0.0 & 14.1 & 28.3\end{array}$}

\section{Figure 6}

Distribution of unit TP load (kg/ha) in DRB in 2010: (a) to (l) represent January to December Note: The designations employed and the presentation of the material on this map do not imply the expression of any opinion whatsoever on the part of Research Square concerning the legal status of any country, territory, city or area or of its authorities, or concerning the delimitation of its frontiers or boundaries. This map has been provided by the authors. 

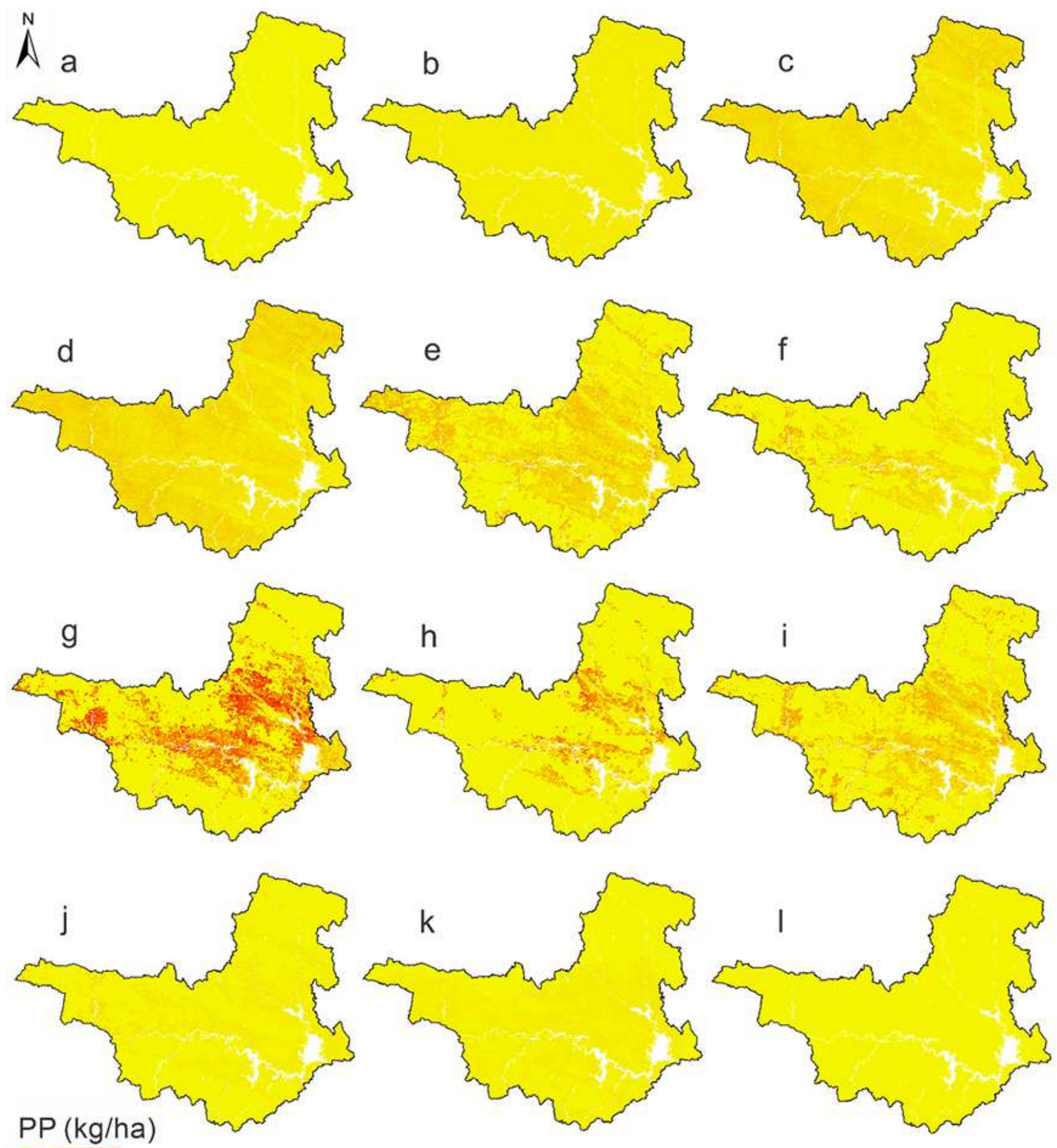

$0.0 \quad 27.8$

\section{Figure 7}

Distribution of unit particulate phosphorus (PP) load (kg/ha) in DRB in 2010: (a) to (l) represent January to December (in the Appendix) Note: The designations employed and the presentation of the material on this map do not imply the expression of any opinion whatsoever on the part of Research Square concerning the legal status of any country, territory, city or area or of its authorities, or concerning the delimitation of its frontiers or boundaries. This map has been provided by the authors. 

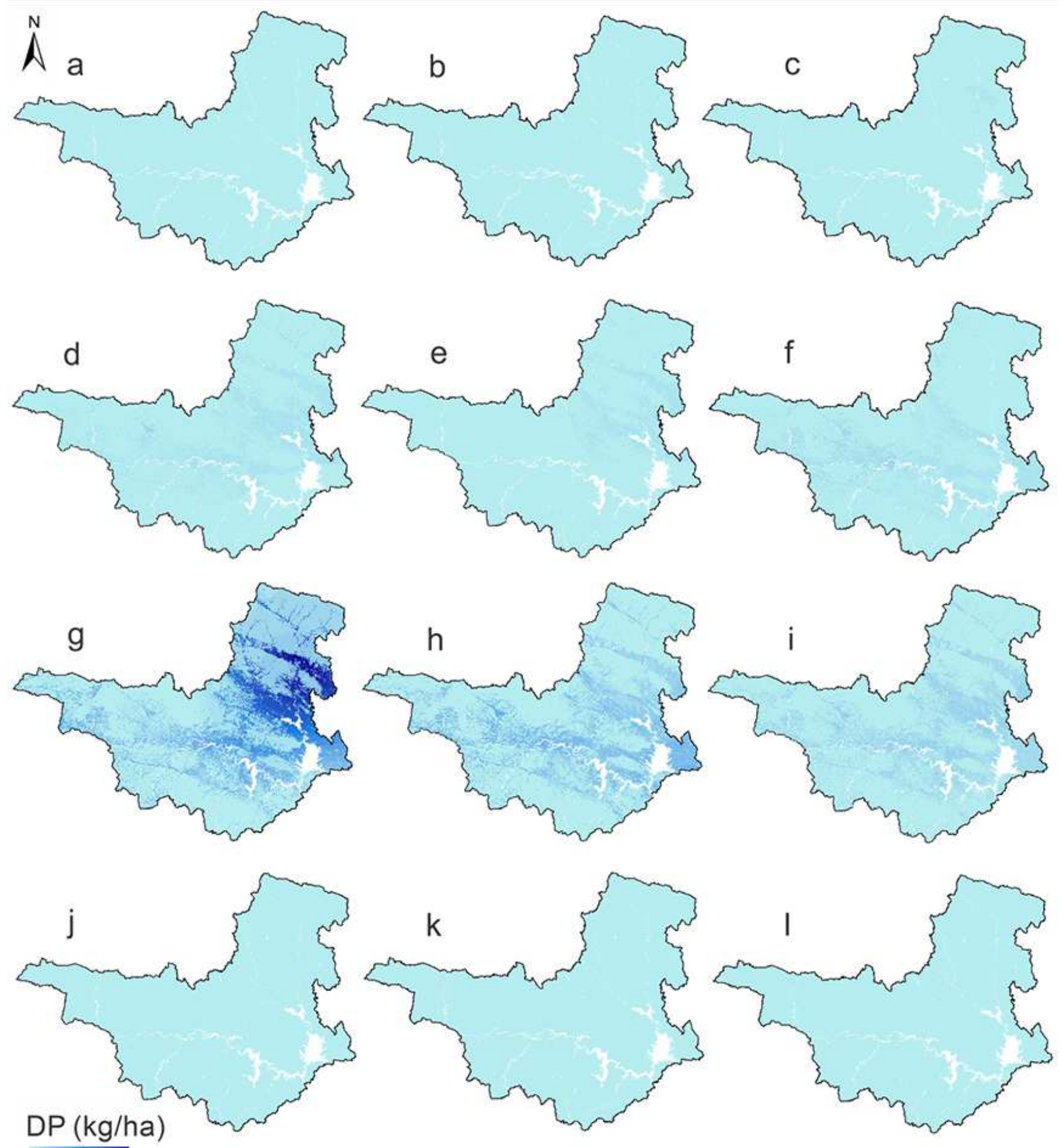

$0.0 \quad 0.6$

\section{Figure 8}

Distribution of unit dissolved phosphorus (DP) load (kg/ha) in DRB in 2010: (a) to (I) represent January to December (in the Appendix) Note: The designations employed and the presentation of the material on this map do not imply the expression of any opinion whatsoever on the part of Research Square concerning the legal status of any country, territory, city or area or of its authorities, or concerning the delimitation of its frontiers or boundaries. This map has been provided by the authors. 

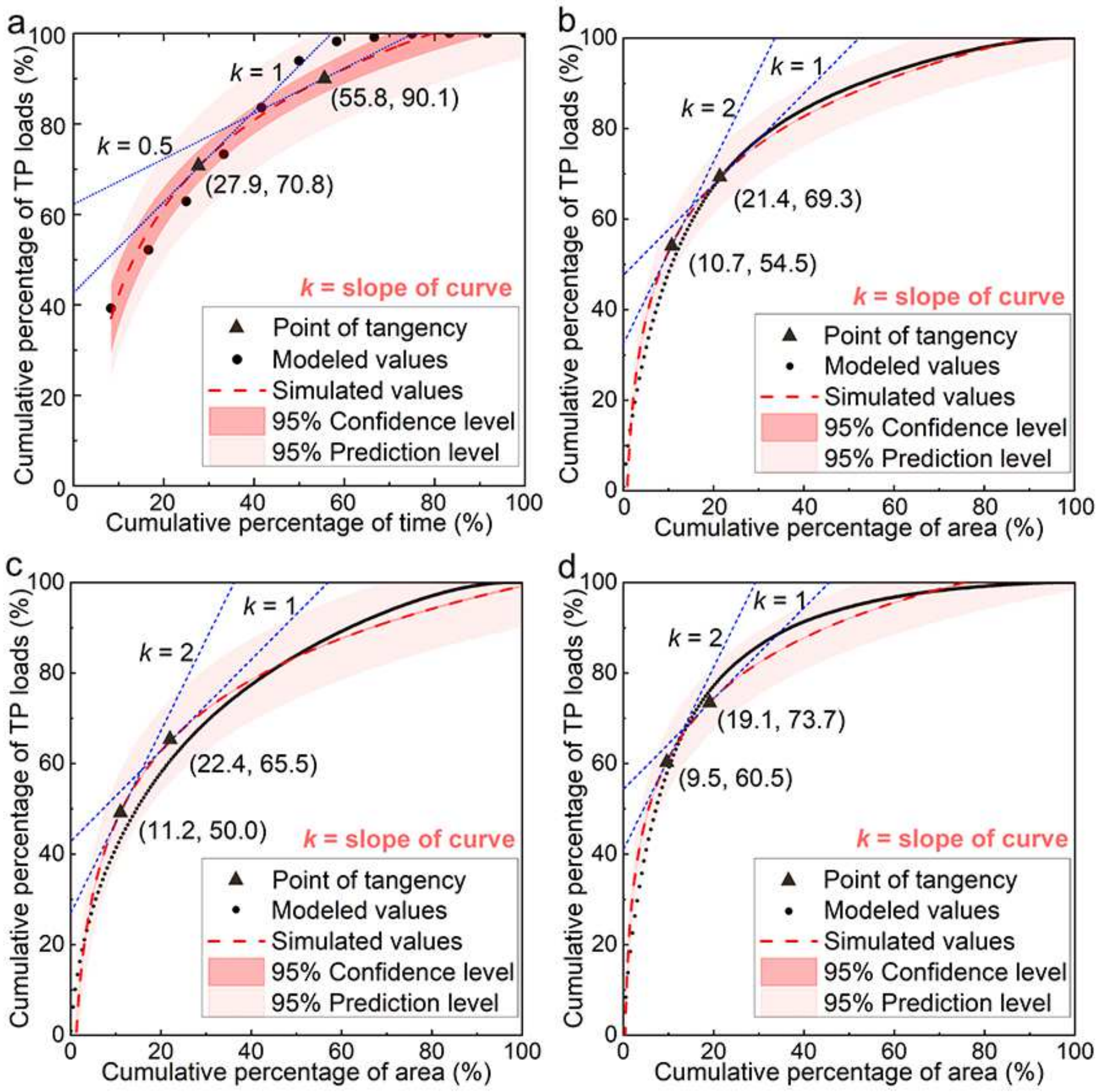

Figure 9

Cumulative load-time fitting curve (a) and cumulative load-area fitting curves ( $b-d)$ : (a) cumulative load-time curve; (b) cumulative load-area curve of CSAs in CPs; (c) cumulative load-area curve of CSAs in sub-CPs; and (d) cumulative load-area curve of CSAs in non-CPs 


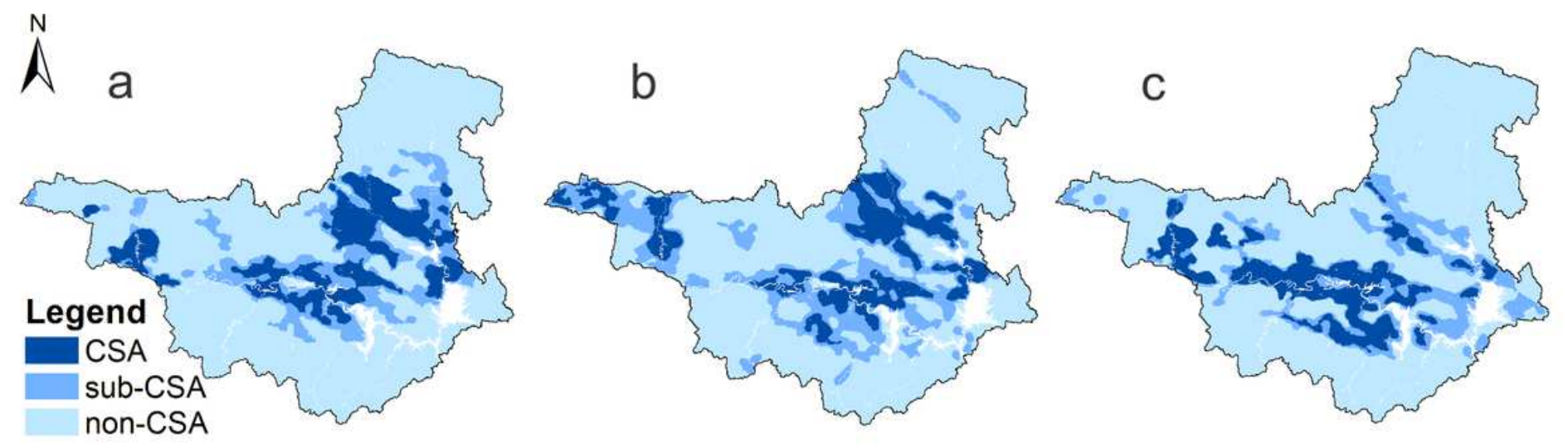

Figure 10

Spatial distribution of CSAs during different periods: (a) in CPs; (b) in sub-CPs; and (c) in non-CPs Note: The designations employed and the presentation of the material on this map do not imply the expression of any opinion whatsoever on the part of Research Square concerning the legal status of any country, territory, city or area or of its authorities, or concerning the delimitation of its frontiers or boundaries. This map has been provided by the authors. 
a

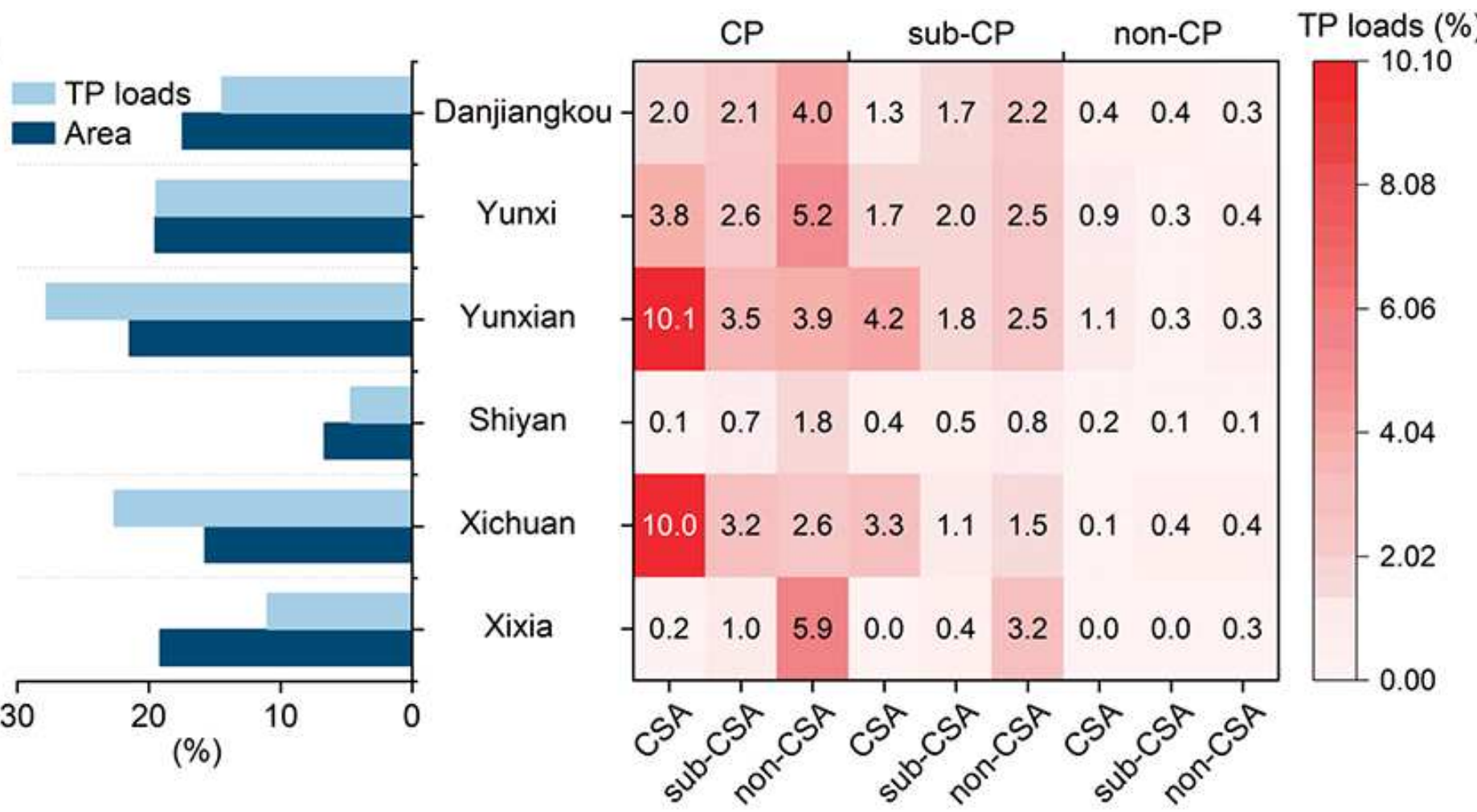

b
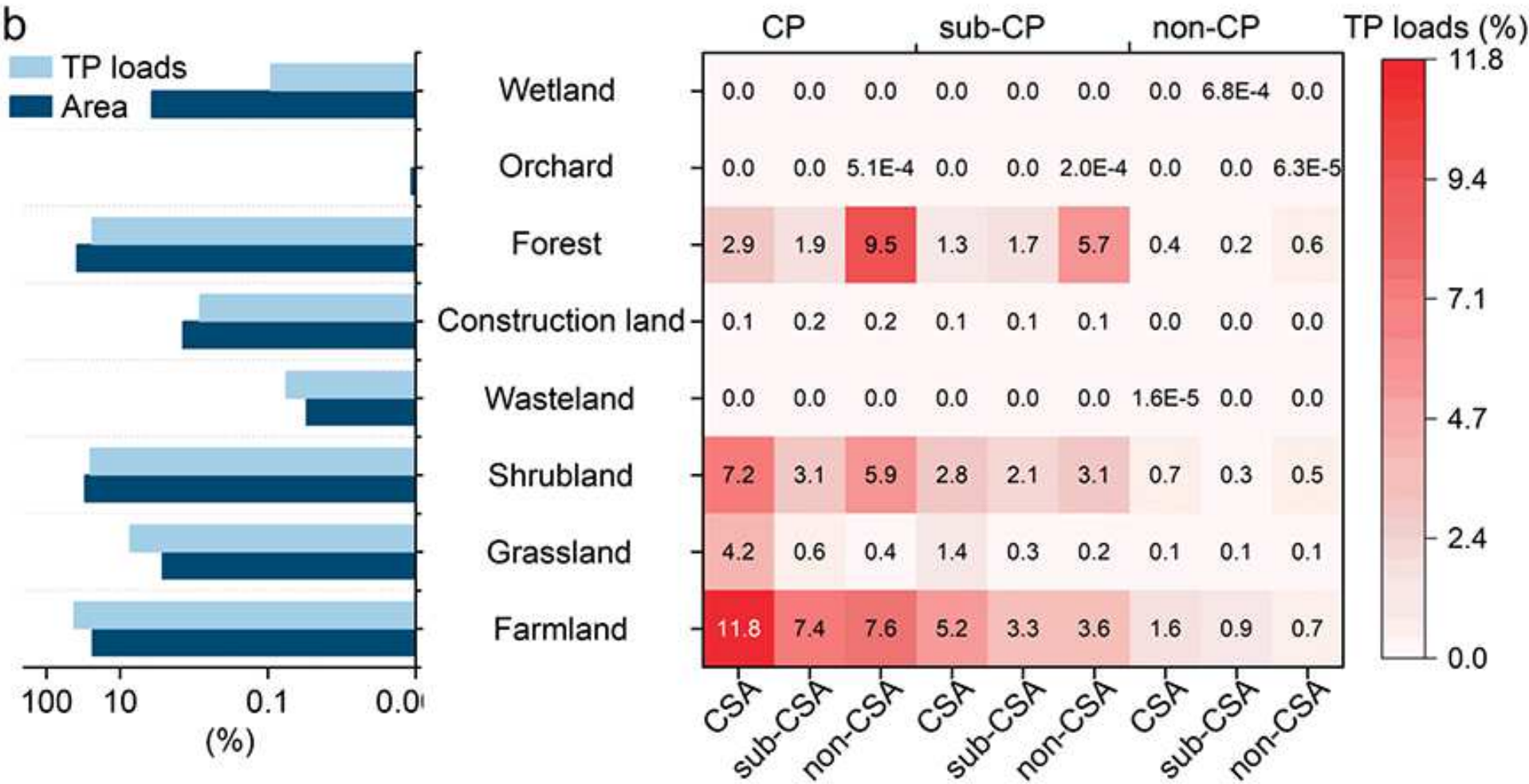

Figure 11

Proportion of TP loads in different periods and areas: (a) within each county and (b) within each land-use type 